\title{
Article \\ Effects of Temperature and Strain Rate on the Ductility of an API X65 Grade Steel
}

\author{
Gabriele Cortis ${ }^{1}\left(\mathbb{D}\right.$, Filippo Nalli ${ }^{1}$, Marco Sasso ${ }^{2, *} \mathbb{C}$, Luca Cortese ${ }^{1}$ and Edoardo Mancini ${ }^{3}(\mathbb{C})$ \\ 1 Department of Mechanical and Aerospace Engineering, Sapienza University of Rome, 00184 Rome, Italy; \\ gabriele.cortis@uniroma1.it (G.C.); fil.nalli@gmail.com (F.N.); luca.cortese@uniroma1.it (L.C.) \\ 2 DIISM, University Politecnica delle Marche, Via Brecce Bianche, 60131 Ancona, Italy \\ 3 DIIIE, University degli Studi dell'Aquila, Piazzale Ernesto Pontieri I, 67100 L'Aquila, Italy; \\ edoardo.mancini@univaq.it \\ * Correspondence: m.sasso@staff.univpm.it
}

Citation: Cortis, G.; Nalli, F.;

Sasso, M.; Cortese, L.; Mancini, E.

Effects of Temperature and Strain

Rate on the Ductility of an API X65

Grade Steel. Appl. Sci. 2022, 12, 2444.

https://doi.org/10.3390/

app12052444

Academic Editor: Elsa Caetano

Received: 18 January 2022

Accepted: 22 February 2022

Published: 26 February 2022

Publisher's Note: MDPI stays neutral with regard to jurisdictional claims in published maps and institutional affiliations.

Copyright: (c) 2022 by the authors. Licensee MDPI, Basel, Switzerland. This article is an open access article distributed under the terms and conditions of the Creative Commons Attribution (CC BY) license (https:// creativecommons.org/licenses/by/ $4.0 /)$.

\begin{abstract}
In the last few decades, great effort has been spent on advanced material testing and the development of damage models intended to estimate the ductility and fracture of ductile metals. While most studies focused on static testing are applied at room temperatures only, in this paper, multiaxial tests have been executed to investigate the effects of dynamic action and temperature on the mechanical and fracture behavior of an API X65 steel. To this end, a Split Hopkinson Bar (SHB) facility for dynamic tests, and a uniaxial testing machine equipped with a high-temperature furnace, were used. Numerical simulations of the experiments were setup for calibration and validation purposes. Based on the experimental results, the Johnson-Cook and Zerilli-Armstrong plasticity models were first tuned, resulting in a good experimental-numerical match. Secondly, the triaxiality and Lode angle dependent damage models proposed by Bai-Wierzbicki and Coppola-Cortese were also calibrated. The comparison of the fracture surfaces predicted by the damage models under different loading conditions showed, as expected, an overall significant increase in ductility with temperature; an appreciable increase in ductility was also observed with the increase in strain rate, in the range of low and moderate triaxialities.
\end{abstract}

Keywords: dynamic tests; high temperature tests; ductile damage; material ductility

\section{Introduction}

Over the years, the requirements, in terms of mechanical performance, of engineering materials have become increasingly more stringent in order to meet the high safety and quality standards expected of modern products and processes. In this scenario, in addition to the identification of the elastic limits related to a safe design under normal operation conditions, it is mandatory to investigate the material's elasto-plastic behavior, ductility, and ultimate strength under all possible operating conditions. This is crucial to assessing the structural integrity of components and mechanical systems under prospective accidental overloads, which might take the material beyond its elastic limits and eventually up to failure.

This design necessity has led to the development of many theoretical and numerical models [1] that try to explain and predict material behavior in terms of both constitutive laws, i.e., stress-strain relationships, and damage evolution, i.e., the combination of conditions determining progressive material degradation up to failure. In this context, the effects of temperature and strain rate can be considered as well, within the framework of visco-plasticity for constitutive relations, and by validating or adapting the existing formulations with regard to ductile damage. Contemporary visco-plastic models are more reliable and consolidated. They can be divided into phenomenological and physical models. The models belonging to the latter category are usually developed by starting from the thermodynamics and kinetics of a dislocation slip [2]. Single- and poly-crystal plasticity 
approaches have been used [3]. Testa et al. [4] developed a flow stress model for BodyCentered Cubic (BCC) materials whose yield stress is decomposed into athermal, thermally activated and viscous drag components. The thermal activation of dislocation motion is the basis of the Zerilli-Armstrong model, which accounts for a material's microstructure by describing two different flow-stress laws for BCC and Face-Centered Cubic (FCC) materials [5]; this model is one of the most commonly adopted formulations in dynamic applications, probably because it is relatively simple and capable of accounting for strain rate and temperature effects in a coupled manner. Many empirical models have been conceived as well, such as those by Cowper and Symonds [6] and Bodner and Partom [7]; one that is widely used is the Johnson-Cook model [8], which addresses the hardening effect of strain rate and the softening effect of temperature with uncoupled multiplicative terms.

Ductile damage has been extensively investigated as well, but mainly under quasistatic conditions [9], while fewer studies have been conducted so far that assess the prediction accuracy of damage models when dynamic conditions or temperature variations are involved. The influence of strain rate on the damage of Advanced High-Strength Steels (AHSS) has been investigated by Khan [10] and Mohr [11]. Oliver [12] and Huh [13] studied Dual-Phase (DP) and Transformation-Induced Plasticity (TRIP) steels, observing a reduction in ductility for DP steels at high strain rates. On the contrary, the ductility of TRIP steel increases with strain rate. DP and TRIP steels were also studied by Huh et al. [14], who noticed a decrease in anisotropy at high strain rates. Depraetere et al. [15] addressed the issue of calibrating a ductile damage model for two API pipeline steels under hydrogenassisted degradation. Wu et al. analyzed the damage evolution pf X52 pipeline steel in the presence of defects [16]. Dong et al. explored how the TRIP effect, and thus tensile strength, are affected by different combinations of temperature and strain rate [17].

As regards damage modeling performed under static loading conditions at room temperature, plenty of theories have appeared in the literature, which are divided into phenomenological and physical theories. With regard to the physical-based models, the seminal works of Rice and Tracey [18], Gurson [19] and Tvergaard and Needleman [20] have stated the relevant role of hydrostatic pressure in the nucleation, growth and coalescence of voids; however, the prediction of shear failure is an issue for this class of models, and modifications have been attempted [21]. In the framework of Continuous Damage Mechanics, Bonora [22] proposed a non-linear model for damage accumulation and failure for different materials, and extended the study to SA537 steel under different strain rates [23]. On the other hand, a number of empirical fracture models have also been established in the literature, such as those by Cockcroft and Latham [24], Johnson and Cook [8], and Bao and Wierzbicki [25], to name a few; more recently, a class of damage models has been derived from the Mohr-Coulomb fracture criterion, based again on the works of Wierzbicki [26-28]. According to this approach, in the context of the several parameters that describe the stress state at a point in a material, it is believed that not only the stress triaxiality, but also the Lode angle, control the evolution of damage up to the final failure of the material. The effectiveness of these models under dynamic conditions has been demonstrated on brittle materials, such as rocks [29], and on ductile metals, such as TRIP steels and AA2024 [11]. A modification of the Bao-Wierzbicki model has been conceived by Coppola et al. [30]; specific functions of triaxiality and Lode related parameters were introduced to describe the fracture surface of API X65 steel under static conditions [31].

In this paper, an attempt is made to investigate how two existing damage models, namely, Bai-Wierzbicki [28] and Coppola-Cortese-Folgarait [30], which were not specifically devised for conditions of high strain rates and large temperature variations, can be adapted and calibrated under dynamic loading conditions, or used for materials subjected to different high temperatures when operating. First, proper analytical formulations are selected from the literature that are able to predict the elasto-plastic constitutive behavior (Johnson and Cook [32], Zerilli and Armstrong [5]), taking into account temperature and strain rate effects. Both plasticity and damage models are intended for use or implementation in Implicit and Explicit Finite Elements Analysis. A calibration strategy based on 
experimental data and inverse methods is identified and proposed for all models. To facilitate robust tuning, different multiaxial tests are set up and executed, specifically tensile tests on round bars, as well as tests on round notched bars and plane strain tests. For temperature tests, a standard uniaxial machine equipped with a high temperature furnace is used, while for dynamic tests, a Split Hopkinson Bar developed by some of the authors is employed [33,34]. The specimens' geometries, facilities' setups and test conditions are optimized to characterize the material under investigation at an average strain rate of about $2000 \mathrm{~s}^{-1}$ and selected temperatures of $600{ }^{\circ} \mathrm{C}$ and $700{ }^{\circ} \mathrm{C}$. These temperatures fall within the range of so-called warm temperatures for steels $\left(550-850{ }^{\circ} \mathrm{C}\right)[35,36]$, which, though well below recrystallization temperatures, are nevertheless high enough to affect the material's mechanical behavior significantly. In this range, it can be assumed that the damage mechanisms do not differ from those that bring a material to failure at room temperature. Due to the limitations imposed by the available facilities, dynamic and temperature effects are studied separately. In addition to the global quantities directly measured during tests, such as load-displacement curves, Finite Element simulations reproducing the experiments are also used to retrieve local non-measurable information at the critical point of each specimen and test.

The investigated material is an API X65 steel, typically used for onshore and offshore oil and gas pipelines, which are possibly subjected to accidental overloading due to excavator bucket impacts [37] or due to anchor and trawl gear impacts [38]. In addition, onshore pipelines could be damaged by the high temperatures resulting from possible fires developing in nearby plants, or by fluid leakage from another pipeline.

The results obtained from the experiments should permit the satisfactory calibration of the plasticity models, whose effectiveness will be proven and presented. This, in turn, would permit us to simulate material behavior at different temperatures and dynamic conditions, and allows the identification of the evolution of the state of stress, plastic strain accumulation and strain at fracture in the material under test conditions. This information is finally used to calibrate the selected damage models, which, once proven to be suitable for use in predicting failure in these new conditions as well, will provide a picture of material ductility and ultimate strength at different temperatures and strain rates.

All the results are also compared with their static and room temperature counterparts, obtained by a previous work of some of the authors [31].

Lastly, the differences in material behavior when moving from static to high strain rate loading conditions, and from room temperature to warm temperatures, are quantified and discussed, along with an assessment of the accuracy and limitations of the selected plasticity and damage formulations.

\section{Numerical Models}

The effects of strain rate and temperature on the ductility of an API X65 grade steel were investigated by selecting and tuning two numerical models to predict material ductile damage accumulation and final fracture. The chosen models rely on material plastic flow to describe the evolution of ductile damage. Consequently, suitable plasticity numerical models capable of taking into account dynamic and temperature effects were required as well. Both the plasticity and damage models adopted in this research are introduced below, along with a description of their calibration procedures.

\subsection{Plasticity Models}

Among the several numerical models that can describe flow stress in a material as a function of strain, strain rate and temperature, two different formulations are considered: the Johnson and Cook (JC) [32] and the Zerilli-Armstrong (ZA) [5]. The JC is a phenomenological model based on Mises Plasticity that accounts for strain hardening, strain rate 
sensitivity and thermal softening. For this reason, it is generally used in adiabatic transient dynamic analyses. The constitutive relation of the model is given by:

$$
\sigma=\left[A+B \varepsilon^{n}\right]\left[1+C \ln \left(\frac{\dot{\varepsilon}}{\dot{\varepsilon_{0}}}\right)\right]\left[1-\left(\frac{T-T_{0}}{T_{\text {melt }}-T_{0}}\right)^{m}\right]
$$

where $\varepsilon$ is the plastic equivalent strain, $\dot{\varepsilon}$ is the plastic strain rate, $\dot{\varepsilon}_{0}$ is a reference strain rate, $T_{0}$ is the room temperature and $T_{\text {melt }} s$ the melting temperature of the material. The first square bracket of Equation (1) refers to strain hardening, and the terms in the second and third square brackets account for strain rate and temperature, respectively. The model is characterized by five material constants: $A$ is the yield strength, $B$ is the hardening coefficient, $n$ is the hardening exponent, $C$ is the sensitivity strain rate coefficient and $m$ is the thermal softening exponent. The limitation of this model is the lack of interaction between the effects of strain rate and temperature, which are regarded as decoupled. It is a model that works best at low temperatures and moderate strain rates $\left(10^{2} \mathrm{~s}^{-1}\right)$.

On the contrary, the second model considered above, i.e., ZA (see Equation (2)), which is based on dislocation mechanisms, regards the effects of strain rate and temperature as coupled, and it is better suited to higher strain rates.

$$
\sigma=\sigma_{0}+C_{1} e^{\left(-C_{3} T+C_{4} T \ln (\dot{\varepsilon})\right)}+C_{5} \varepsilon^{n}
$$

Furthermore, it is a model that considers the effects of the internal structure of the material on its plastic behavior. In fact, there are two different expressions, one for materials with a Body-Centered Cubic structure (BCC) and one with a Face-Centered Cubic structure (FCC). Equation (2) is for BCC structures and is characterized by six material constants: $\sigma_{0}$, $C_{1}, C_{3}, C_{4}, C_{5}$ and $n$, the strain hardening exponent.

The material constants of both models can be derived through the following inverse procedure with the aid of the finite element method. A suitable number of dynamic experimental tests are carried out under different conditions, namely, a tensile test on round bar (RB) and round notched bar specimens (RN), and a test under plane strain (PS) conditions, and the experimental load-displacement curves are derived. Afterwards, a finite element model of the experimental tests is carried out in which the material behavior is described by the plasticity model to be calibrated. Through a trial and error minimization procedure, several finite element simulations are performed by varying the material constants until a load-displacement curve as close as possible to that found experimentally is obtained.

\subsection{Ductile Damage Models}

Two models are considered in this work, the Bai-Wierzbicki model (BW) [28] and the Coppola-Cortese-Folgarait (CCF) [30], both of which fall in the class of empirical models. Under these models, damage is supposed to accumulate with equivalent plastic strain $\varepsilon_{p}$, as follows:

$$
D=\int_{0}^{\varepsilon_{f}} f(T, X) d \varepsilon_{p}
$$

where the evolution of ductile damage $D$ is described by the integral of the function $f(T, X)$ between the zero plastic strain and the maximum admissible strain at failure $\varepsilon_{f}$. The parameters T, Equation (4), and X, Equation (5), govern the damage evolution and are called the triaxiality and Lode parameters, respectively. They in turn depend on the stress state of the material, indicated through the first invariant of the stress tensor $I_{1}$, and the second and third invariants of the deviatoric stress tensor, $J_{2}$ and $J_{3}$.

$$
\begin{gathered}
T=\frac{1}{3} \frac{I_{1}}{\sqrt{3 J_{2}}} \\
X=\frac{27}{2} \frac{J_{3}}{\left(\sqrt{3 J_{2}}\right)^{3}}
\end{gathered}
$$


Fracture onset occurs when $D$ reaches a critical value, conventionally set at 1 . Under the hypothesis of proportional loading, which implies constant $T$ and $X$, by posing a $D$ equal to one and inverting Equation (3), the following expression is obtained:

$$
\varepsilon_{f}=f^{-1}(T, X)
$$

The graphical representation of such a function is a three dimensional surface in the space $\left(T, X, \varepsilon_{p}\right)$, commonly named the "fracture surface"; for each couple of $(T, X)$, i.e., a specific stress state, a specific value of plastic strain is computed that coincides with the onset of failure. Generally, proportional loading conditions are not satisfied because $T$ and $X$ are not perfectly constant, and the deformation and necking onset may be further affected by temperature and strain rate variations occurring during the tests [39]. However, we here assume the average values of the two parameters $T_{a v g}$, Equation (7), and $X_{a v g}$, Equation (8), in order to meet the proportional or quasi proportional loading hypothesis, and use Equation (6) to derive the fracture surface.

$$
\begin{aligned}
& T_{\text {avg }}=\frac{1}{\varepsilon_{f}} \int_{0}^{\varepsilon_{f}} T(\varepsilon) d \varepsilon_{p} \\
& X_{a v g}=\frac{1}{\varepsilon_{f}} \int_{0}^{\varepsilon_{f}} X(\varepsilon) d \varepsilon_{p}
\end{aligned}
$$

The models adopted in this work are characterized by a different function $f^{-1}(T, X)$. In Equations (9) and (10), the analytical expressions of the BW and CCF models are reported [28,30].

$$
\begin{gathered}
\varepsilon_{f}=\left\{\frac{K}{C_{2}}\left[\sqrt{\frac{1+C_{1}^{2}}{3}} \cos \cos \left(\frac{\pi}{6}-\theta\right)+C_{1}\left(T+\frac{1}{3} \sin \sin \left(\frac{\pi}{6}-\theta\right)\right)\right]\right\}^{-\frac{1}{n}},(\mathrm{BW}) \\
\varepsilon_{f}=\frac{1}{c_{1}} e^{-c_{2} T}\left(\frac{\cos \left[\beta \frac{\pi}{6}-\frac{1}{3} \arccos (\gamma)\right]}{\cos \left[\beta \frac{\pi}{6}-\frac{1}{3} \arccos (X \gamma)\right]}\right),(\mathrm{CCF})
\end{gathered}
$$

$K$ and $n$ are, respectively, the strength coefficient and strain hardening exponent of Hollomon's power law $\sigma=K \varepsilon^{n}$. The Lode angle is used in place of the Lode parameter $X$ in the BW expression, Equation (9). The following relation holds between the two:

$$
\theta=\frac{1}{3} \arccos X
$$

The first model is characterized by only two material constants, $C_{1}$ and $C_{2}$, if the Von Mises yielding condition is adopted, while the second is characterized by four constants, $C_{1}, C_{2}, \beta$ and $\gamma$. The constants of both models can be identified for a specific material using the following calibration procedure. A suitable number of experimental tests are executed under different loading conditions, usually tensile tests (RB, RN), plane strain tensile tests (PS) or torsion tests, and the resulting global quantities, load and displacement at failure, are measured and recorded. Since it is not possible to retrieve the local quantities $T_{a v g}, X_{a v g}$ and $\varepsilon_{f}$ from direct measurements, it is necessary to perform a finite element simulation for each experimental test, using the constitutive models previously calibrated as explained in 2.1, in order to locally identify the principal stresses and the failure strain at the critical point. As a result, a unique point with coordinates $\left(T_{a v g}, X_{a v g}, \varepsilon_{f}\right)$ for each specimen can be obtained. All of these points serve as an input for the calibration process, as the fracture surface is dependent on them. Through a minimization algorithm, the calibration constants are derived in order to obtain the lowest possible standard deviation (SD) between the failure strains computed in the experiments via the inverse method and 
the failure strains predicted by the damage model $\left(\varepsilon_{f}^{\text {model }}\right)$. The error function of the algorithm is based on the following formula:

$$
S D=\sqrt{\frac{1}{N-1} \sum_{i=1}^{N}\left(\varepsilon_{f, i}^{m o d e l}-\varepsilon_{f, i}\right)^{2}}
$$

where $n$ is the total number of tests and $i$ corresponds to the i-th specimen. The outcomes of the procedure are the material constants of the fracture surface of the models (Equations (9) and (10)) that best fit the experimental points.

\section{Experimental Setup and Testing}

The material chosen for the experimental campaign is an API grade X65, commonly employed in the production of pipelines for onshore and offshore applications. Its mechanical characterization was carried out in a previous work by some of the authors. The material can be regarded as isotropic, since the pipes from which the specimens have been extracted were subjected to quenching and tempering, which removed any anisotropy induced by the pipe-forming process itself. The main mechanical and physical properties of the X65 are presented in Table 1; refer to [31] for further details on the material.

Table 1. API X65 mechanical properties taken from [31].

\begin{tabular}{ccccccc}
\hline Material & Delivery State & $\begin{array}{c}\text { Density } \\
\left(\mathbf{k g} / \mathbf{m}^{\mathbf{3}}\right)\end{array}$ & $\begin{array}{c}\text { Specific Heat } \\
\left(\mathbf{J} /\left(\mathbf{k g}{ }^{\circ} \mathbf{C}\right)\right.\end{array}$ & $\begin{array}{c}\text { Yield Stress } \\
\mathbf{( M P a})\end{array}$ & $\begin{array}{c}\text { Ultimate Stress } \\
(\mathbf{M P a})\end{array}$ & $\begin{array}{c}\text { Elongation at Fracture } \\
\mathbf{( \% )}\end{array}$ \\
\hline API X65 & $\begin{array}{c}\text { Quenched } \\
\text { and tempered }\end{array}$ & 7800 & 486 & 464 & 530 & 18 \\
\hline
\end{tabular}

\subsection{Dynamic Setup for High Strain Rate Tests}

The first use of long and thin rods to measure the pressure waves produced by impacts was reported by Hopkinson [40] in 1914, and later improved through the work of Kolsky [41]. The Hopkinson bar technique, initially introduced for compression tests, was later extended to tensile and torsion tests as well [42], and is typically used to carry out tests at high strain rates, ranging from $10^{2}$ to $10^{4} \mathrm{~s}^{-1}$.

In this work, a direct tension Hopkinson bar (SHTB) is used, consisting of three aligned bars, named the pre-stressed, input and output bars. A tensile input wave $\left(\sigma_{i}, \varepsilon_{i}\right)$ is generated by pre-loading the pre-stressed bar with compression, and by the subsequent sudden release of this pre-load (Figure 1a). The release of the pre-load is accomplished by the failure of a brittle sacrificial element; the strength of this element governs the input wave amplitude.

The input wave $\left(\sigma_{i}, \varepsilon_{i}\right)$ travels at the speed of sound along the input bar; when it reaches the input bar-sample interface, part of the wave is reflected back into the input bar as a reflected wave $\left(\sigma_{r}, \varepsilon_{r}\right)$, and the other part propagates through the sample and travels along the output bar as a transmitted wave $\left(\sigma_{t}, \varepsilon_{t}\right)$. While the bars remain within their elastic limit, the sample deforms plastically. The reflected and transmitted strain waves are acquired by means of properly placed strain gauge rosettes; assuming uniaxial wave propagation in the bars and dynamic equilibrium in the sample, the engineering strain rate, strain and flow stress of the sample material can be obtained from the following formulas:

$$
\begin{gathered}
\sigma(t)=\frac{A_{b} E_{b}}{A_{s}} \varepsilon_{t}(t) \\
\dot{\varepsilon}(t)=-\frac{2 C_{0}}{L_{s}} \varepsilon_{r}(t) \\
\varepsilon(t)=-\frac{2 C_{0}}{L_{s}} \int_{0}^{t} \varepsilon_{r}(t) d t
\end{gathered}
$$




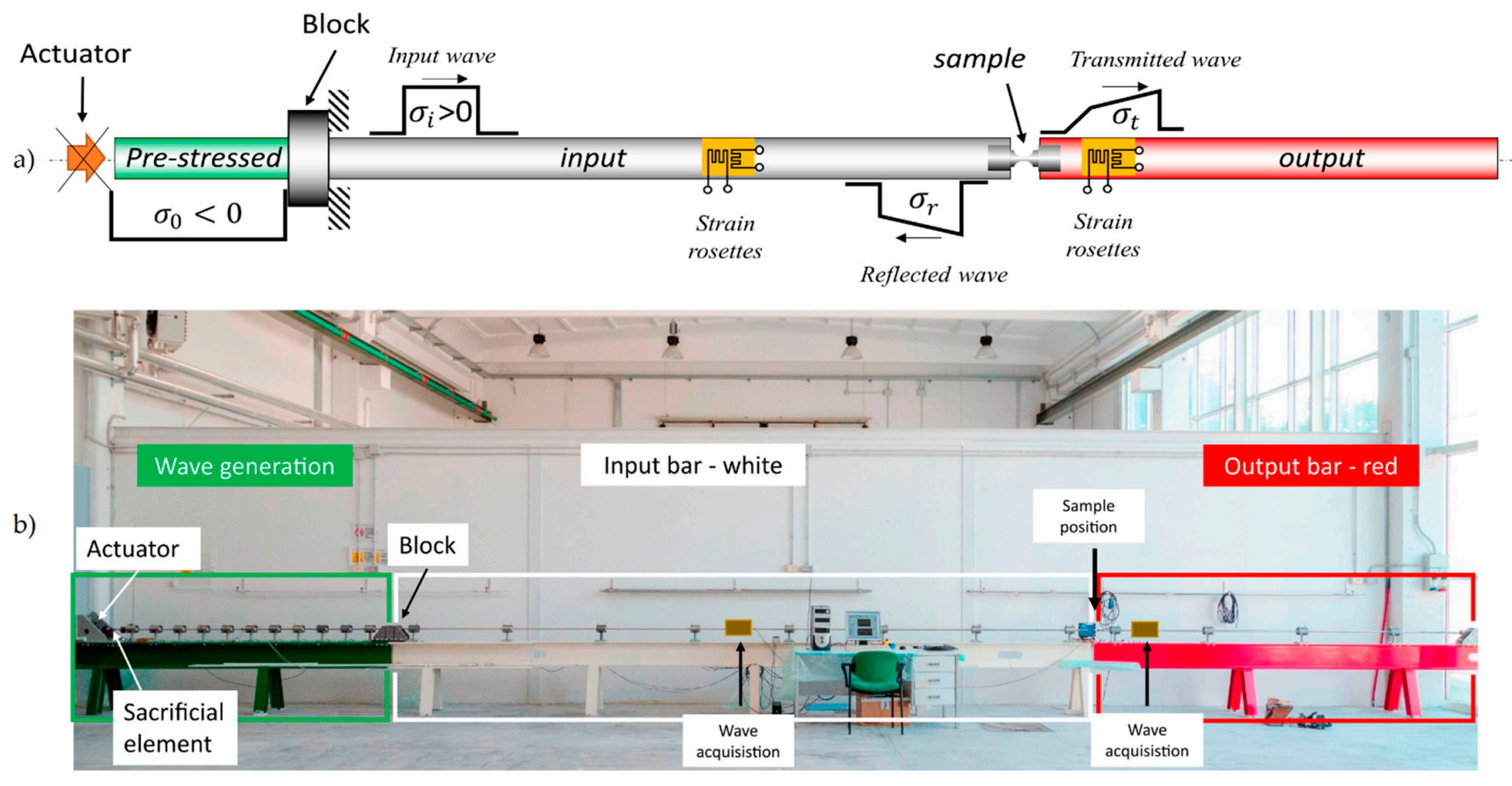

Figure 1. (a) Scheme of the direct Split Hopkinson bar, (b) direct Split Hopkinson bar facility [33].

Figure $1 \mathrm{~b}$ shows the direct Split Hopkinson bar facility used in this work [33,34].

\subsubsection{Optimization of Samples for Dynamic Tests}

The geometries of the samples used in dynamic tests basically consist of modifications of those used in quasi-static tests, with the intention of adapting the sample to the equipment available for the dynamic testing described in the previous section. In fact, the dynamic test samples must meet the geometrical requirements for being mounted on the experimental facility (by means of M12 threads), and they must have the proper lengths and section sizes in order to be successfully tested up to failure with the displacements and forces allowed by the adopted SHB. An example of the adapted sample geometries is reported in Figure 2.
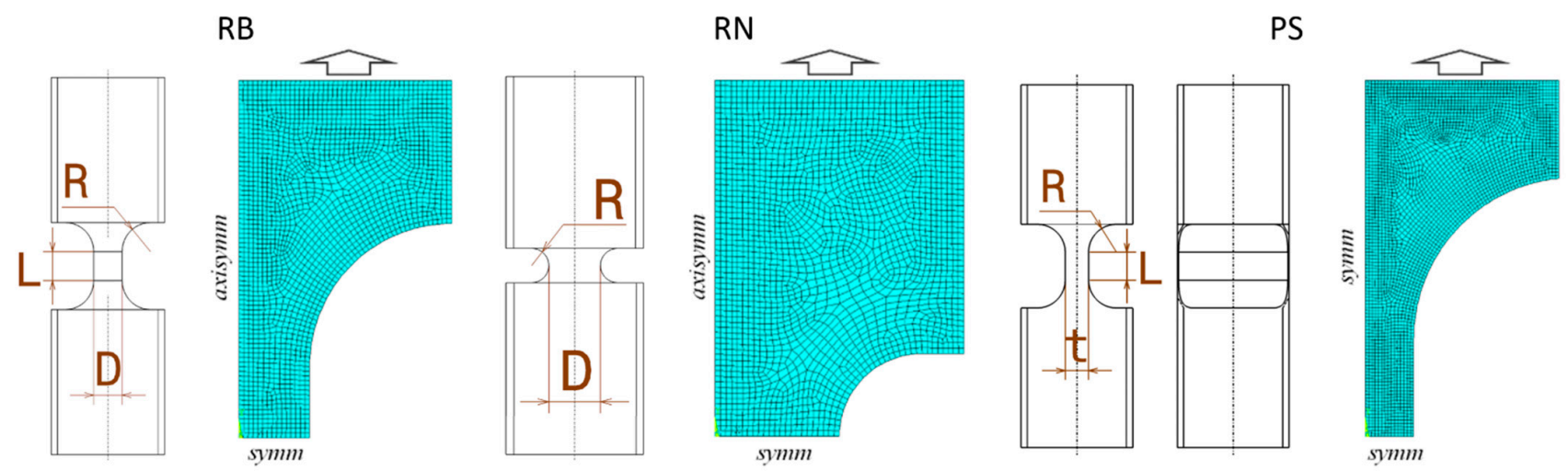

Figure 2. Shapes of test samples used in dynamic tests and FEM models used for their optimization.

An inverse optimization procedure was numerically implemented in order to define the geometric parameters of the samples reported in Figure 2, which would allow us to obtain the desired stress and strain evolutions in the sample. The targets of such optimization are:

- average strain rate of about $2000 \mathrm{~s}^{-1}$ for all three geometries;

- equivalent plastic strain rate at the specimen core that is as constant as possible; 
- triaxiality at the specimen core that is as constant as possible;

- much higher triaxiality in the round notch specimen (RN) than in the round bar (RB) and plane strain specimens (PS).

The input parameters to be optimized are gauge length $L_{0}$, fillet radii $R$, section diameter $D$ for the RB and RN specimens, thickness $t$ for the PS specimen, and impact speed or, equivalently, incident wave amplitude $\sigma_{i}$.

The optimization is conducted by launching several finite element simulations with the ANSYS ${ }^{\circledR}$ commercial FE code. The mesh and boundary conditions are also illustrated in Figure 2. The RB and RN sample models are 2D axisymmetric, while the PS sample model is $2 \mathrm{D}$ plane strain. The bottom edges of the models representing the symmetry plane are constrained in the axial direction, while a positive axial displacement is applied to the top edge. Since the behavior of the material at high strain rates is not, the plastic flow curve of the material is assumed to be represented by the quasi-static curve given in the previous section, increased by a tentative dynamic correction factor of 1.08 , accounting for the possible strain rate sensitivity. More details on the numerical procedure, especially about the method used for generating a reasonable displacement history, are given in a previous work by some of the authors [43].

A full factorial Design of Experiments plane has been simulated for each of the three geometries by varying the input parameters on several levels, for a total of approximately 450 simulations. The output parameters of each simulation are the time averages of the plastic strain rate and of the triaxiality, as well as their variance over time, and the maximum equivalent plastic strain that can be reached with the given incident wave amplitude. For instance, Figure 3 illustrates the trends of the average triaxiality, the average strain rate and the maximum equivalent plastic strain for the RB, RN and PS geometries, reconstructed as continuous response surfaces (second-order polynomial) that best fit the results of the 450 simulations.

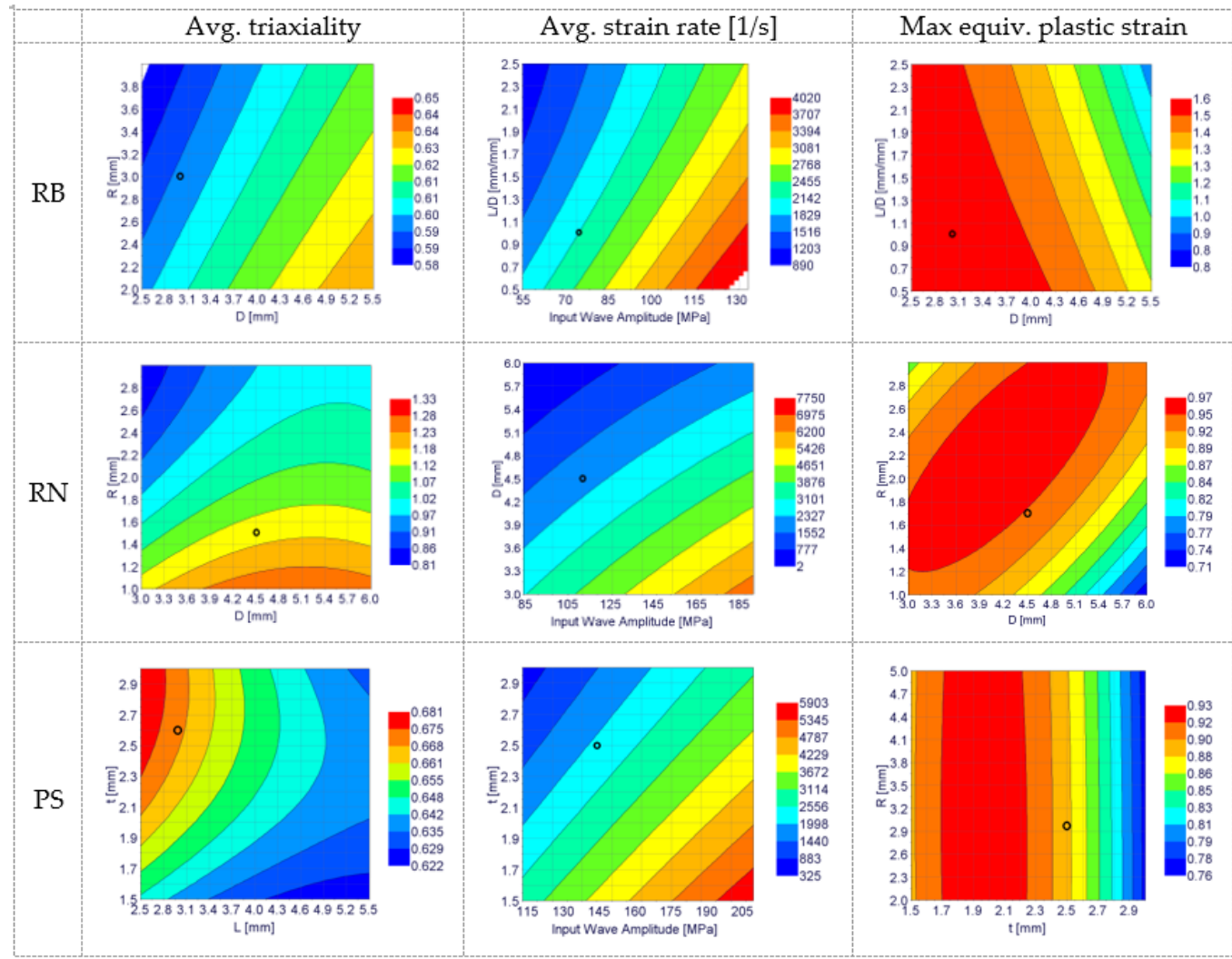

Figure 3. Response surfaces (the black markers refer to the selected geometries). 
In order to select the best combination of input parameters, a cost function has been defined as follows:

$$
\cos t=\sum_{g}\left\{\frac{\sqrt{\sum_{t}\left[T_{g}(t)-\bar{T}_{g}\right]^{2}}}{\overline{T_{g}}}+\frac{\sqrt{\sum_{t}\left[\dot{\varepsilon}_{g}(t)-\overline{\dot{\varepsilon}_{g}}\right]^{2}}}{\overline{(\dot{\varepsilon})}}\right\} \cdot\left\{\frac{2 \overline{\bar{T}}}{\left|\bar{T}_{R B}+\bar{T}_{P S}-2 \bar{T}_{R N}\right|}\right\} \cdot \frac{\sqrt{\sum_{g}\left(\overline{\dot{\varepsilon}_{g}}-\overline{\dot{\varepsilon}}\right)^{2}}}{\overline{\bar{\varepsilon}}}
$$

where index $g$ spans the three geometries (RB, RN, PS), the upper bar denotes the time average and the double upper bar denotes the average among the different geometries. The goal is to find the combination of input parameters that minimizes the cost function, in order to obtain triaxiality and strain rates that remain as constant as possible during the tests, and to achieve similar average strain rates in the three geometries. Furthermore, the problem has been stated as a constrained optimization; in fact, only those design configurations that are predicted to reach an equivalent strain to failure higher than the corresponding value under quasi-static conditions (incremented by a safety margin of $20 \%$ ) have been considered as acceptable.

The selected specimens' geometric parameters and test speed are reported in Table 2; they correspond to the coordinates of the black markers reported on the response surfaces in Figure 3. Table 2 also shows the estimated values of average strain rate, average triaxiality, their standard deviation (SD) and the maximum equivalent plastic strain at the core of the samples. The SD values show that, as expected, the triaxiality and strain rate cannot be constant; however, the resulting configuration is the one that minimizes the function reported in Equation (16). Figure 4 shows the expected temporal evolution of stress triaxiality and plastic strain rate.

Table 2. Optimized geometric parameters and predicted results.

\begin{tabular}{|c|c|c|c|c|c|c|c|c|c|}
\hline \multirow{3}{*}{$\begin{array}{l}\text { Geom. } \\
\text { Type }\end{array}$} & \multirow{2}{*}{$\mathrm{D} / \mathrm{t}$} & \multirow{2}{*}{$\mathbf{L}$} & \multirow{2}{*}{$\mathbf{R}$} & \multirow{2}{*}{$\begin{array}{c}\text { Wave Amp. } \\
\sigma_{I}\end{array}$} & \multicolumn{2}{|c|}{ Plastic Strain Rate } & \multicolumn{2}{|c|}{ Triaxiality } & \multirow{2}{*}{$\begin{array}{l}\text { Max Equiv. } \\
\text { Plastic Strain }\end{array}$} \\
\hline & & & & & Avg. & $\pm \mathrm{SD}$ & Avg. & $\pm \mathrm{SD}$ & \\
\hline & $(\mathrm{mm})$ & $(\mathrm{mm})$ & $(\mathrm{mm})$ & (MPa) & $(1 / s)$ & $(1 / \mathrm{s})$ & $(-)$ & $(-)$ & $(\mathrm{mm} / \mathrm{mm})$ \\
\hline $\mathrm{RB}$ & 3 & 3 & 3 & 75 & 2200 & 700 & 0.59 & 0.15 & 1.52 \\
\hline $\mathrm{RN}$ & 4.5 & - & 1.5 & 110 & 2000 & 440 & 1.16 & 0.02 & 0.94 \\
\hline PS & 2.5 & 3 & 3 & 140 & 2100 & 740 & 0.67 & 0.08 & 0.89 \\
\hline
\end{tabular}

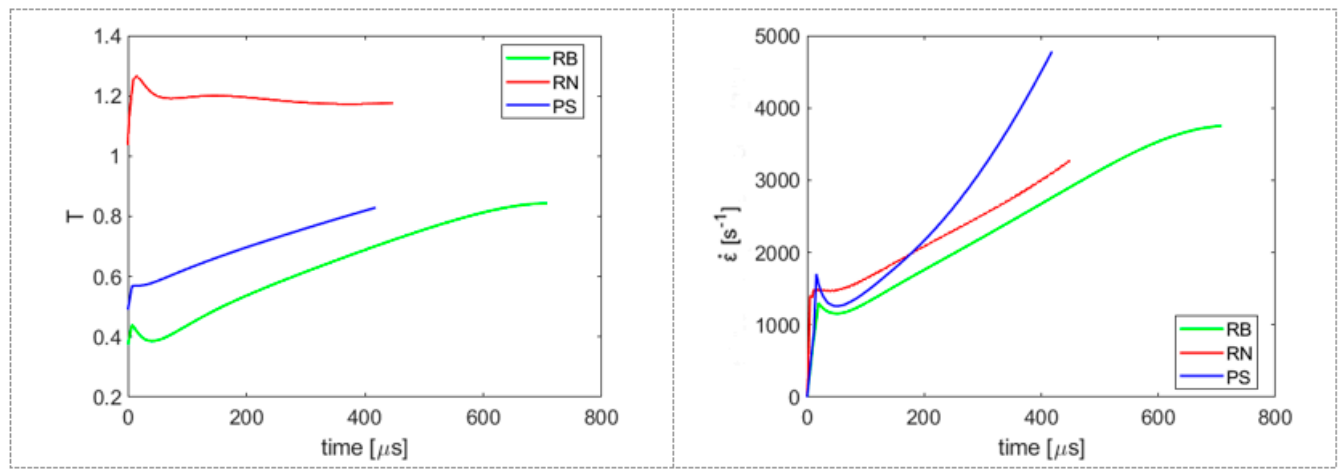

Figure 4. Estimated triaxiality and strain rate as a function of time for the selected specimen geometries and input wave amplitude.

It has to be noted that the strain rate is reasonably similar among the three test conditions, and the triaxiality in the RN sample is significantly greater than in the other two geometries. The predicted equivalent plastic strain is also high enough for us to be reasonably certain that the specimens will break in real experimental conditions. 


\subsection{Setup for Static Temperature Tests}

Figure 5 shows the three specimen geometries selected for the tests at warm temperatures: a standard tensile specimen (RB) for uniaxial tests, a round notched bar with a notch radius of $2 \mathrm{~mm}(\mathrm{RN})$, and a plane strain geometry (PS) for multiaxial tests. The specimens heads are threaded (M12) for them to be mounted in the proper custom high-temperature grips of the testing equipment.

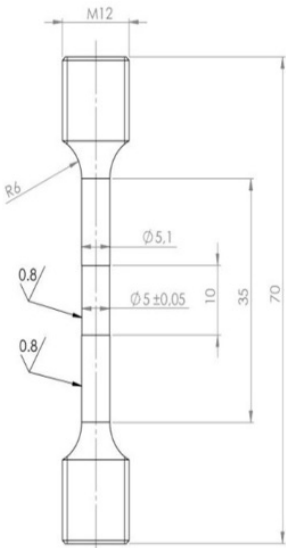

(a)

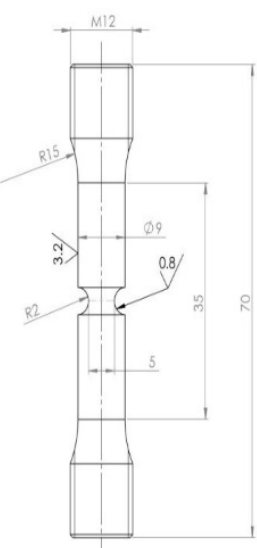

(b)
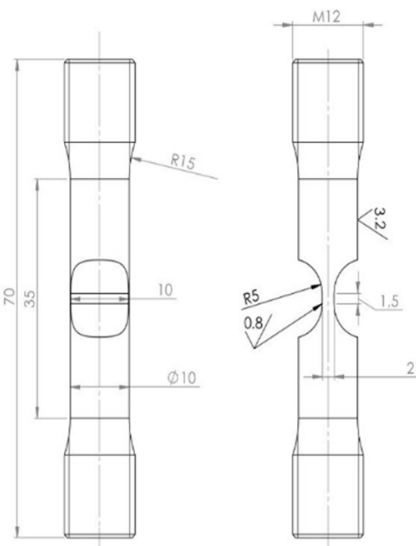

(c)

Figure 5. Specimen geometries: (a) round bar; (b) round notched bar; (c) plane strain.

All tests are executed using a Material Testing System (MTS) Criterion 45.105 universal machine, equipped with a two-zone MTS 684 furnace capable of raising sample temperatures up to $1000^{\circ} \mathrm{C}$. The test chamber of the furnace has a volume of $50 \times 50 \times 50 \mathrm{~mm}^{2}$. The furnace is controlled by an MTS 409.83 , while specimen temperature is measured by two high-temperature thermocouples, fixed to the specimen itself. Axial gauge section elongation is measured by a high-temperature MTS extensometer with ceramic legs and a base length of $25 \mathrm{~mm}$, which can be put in contact with the specimen through a dedicated fence placed in the furnace. Figure 6 illustrates some details of the experimental facility.

a)
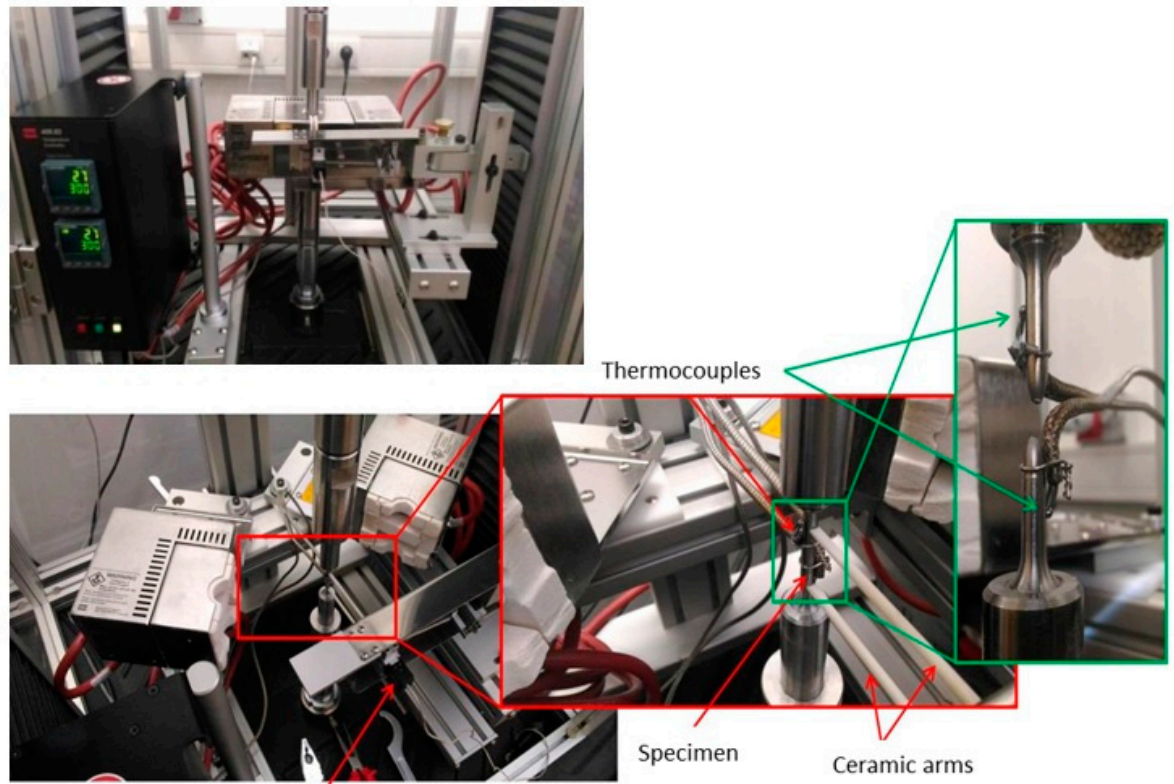

High temp extensometer

Ceramic arms

Specimen

Figure 6. Experimental setup. (a) MTS testing equipment for high-temperature tests. (b) Details of specimens, fixtures, thermocouples and extensometer. 
The MTS TW Elite test software is used for test execution and data acquisition. The tests are conducted with control of displacement, and with constant speeds of $1 \mathrm{~mm} / \mathrm{s}$ (RB), $0.25 \mathrm{~mm} / \mathrm{s}$ (RN2) and $0.5 \mathrm{~mm} / \mathrm{s}$ (PS), which are conditions that could be regarded as quasi-static. During runs, data from the load cell, displacement transducer, extensometer and thermocouples are acquired. Two temperatures are tested, based on results from the literature: $700{ }^{\circ} \mathrm{C}$, which falls in the middle of the typical warm temperature range $\left(600-800{ }^{\circ} \mathrm{C}\right.$ ) for steels, and $600{ }^{\circ} \mathrm{C}$, which is regarded by some authors [44] as the best choice for warm forming in terms of cost/benefits. Some preliminary tests were executed at a temperature of $300{ }^{\circ} \mathrm{C}$. In this case, no appreciable differences were found from tests executed at room temperature.

\section{Dynamic Tests: Results and Discussion}

The SHB facility described in Section 3.1 was used to conduct tensile tests at a high strain rate on the optimized sample geometries described in Table 2. Three repetitions were performed for each test condition, and excellent repeatability was observed. Figure 7 summarizes the typical results in terms of load and engineering strain rate versus time. The load is easily derivable using Equation (13). The engineering strain rate was computed by applying Equation (14) to the reflected waves measured experimentally during the tests; for comparison purposes, an initial gauge length $\mathrm{L}_{\mathrm{S}}$ of $3.0 \mathrm{~mm}$ was used for all three geometries.

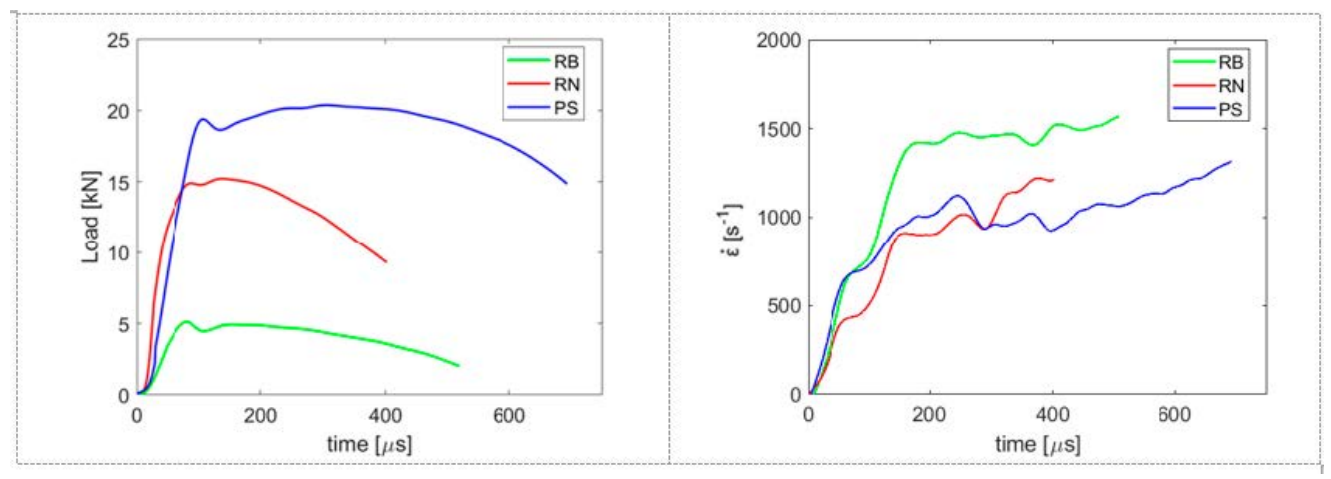

Figure 7. Load vs. time and engineering strain rate vs. time for three different specimen geometries tested at high strain rates.

The experimental results in terms of load vs. time were processed using the procedure of Section 2.1, which aims at the accurate calibration of the JC and ZA plasticity models. The FE models are analogous to those used in the geometry optimization described in Figure 2, Section 3.1.1, with exceptions made for the PS geometry, which was extruded, along the width direction, to perform a more accurate 3D analysis. Moreover, the selfheating effect was considered, converting the plastic work into heat. Specifically, this conversion was done by imposing a Taylor-Quinney coefficient equal to 1, while the material density and specific heat were set at $7800 \mathrm{~kg} / \mathrm{m}^{3}$ and $486 \mathrm{~J} /\left(\mathrm{kg}{ }^{\circ} \mathrm{C}\right)$, respectively. The boundary conditions were applied to the numerical models replicating the real elongations measured in Hopkinson bar tests. ANSYS explicit code (Autodyn ${ }^{\circledR}$ ) was used as the FE solver, while the optimization was driven by the ANSYS Workbench ${ }^{\circledR}$ optimization module with the response surface and genetic algorithm MOGA [43].

The material constants for the API X65, resulting from the inverse procedure, are reported in Tables 3 and 4 . Figure 8 provides a comparison of the load-displacement experimental curves with those obtained by the FE simulations. In Figure 8, the numerical counterpart of the experimental results is also reported. A good agreement can be observed in all cases, which confirms that both the JC and ZA models are suitable for use to describe material behavior at high strain rates. 
Table 3. Material constants, JC model.

\begin{tabular}{ccccc}
\hline \multicolumn{5}{c}{ Johnson-Cook } \\
\hline $\begin{array}{c}\boldsymbol{A} \\
(\mathbf{M P a})\end{array}$ & $\begin{array}{c}\boldsymbol{B} \\
\mathbf{M P a})\end{array}$ & $\begin{array}{c}\boldsymbol{( - )} \\
\text { (-) }\end{array}$ & $\begin{array}{c}\boldsymbol{C} \\
(-)\end{array}$ & $\begin{array}{c}\boldsymbol{m} \\
(-)\end{array}$ \\
\hline 464 & 401 & 0.439 & 0.047 & 0.464 \\
\hline
\end{tabular}

Table 4. Material constants, ZA model.

\begin{tabular}{cccccc}
\hline \multicolumn{7}{c}{ Zerilli-Armstrong } \\
\hline $\begin{array}{c}\sigma_{0} \\
(\mathbf{M P a})\end{array}$ & $\begin{array}{c}C_{1} \\
\mathbf{M P a}\end{array}$ & $\begin{array}{c}C_{3} \\
(-)\end{array}$ & $\begin{array}{c}C_{4} \\
(-)\end{array}$ & $\begin{array}{c}C_{5} \\
(\mathbf{M P a})\end{array}$ & $\begin{array}{c}n \\
(-)\end{array}$ \\
\hline 363 & 668 & 0.004 & 0.001 & 401 & 0.439 \\
\hline
\end{tabular}
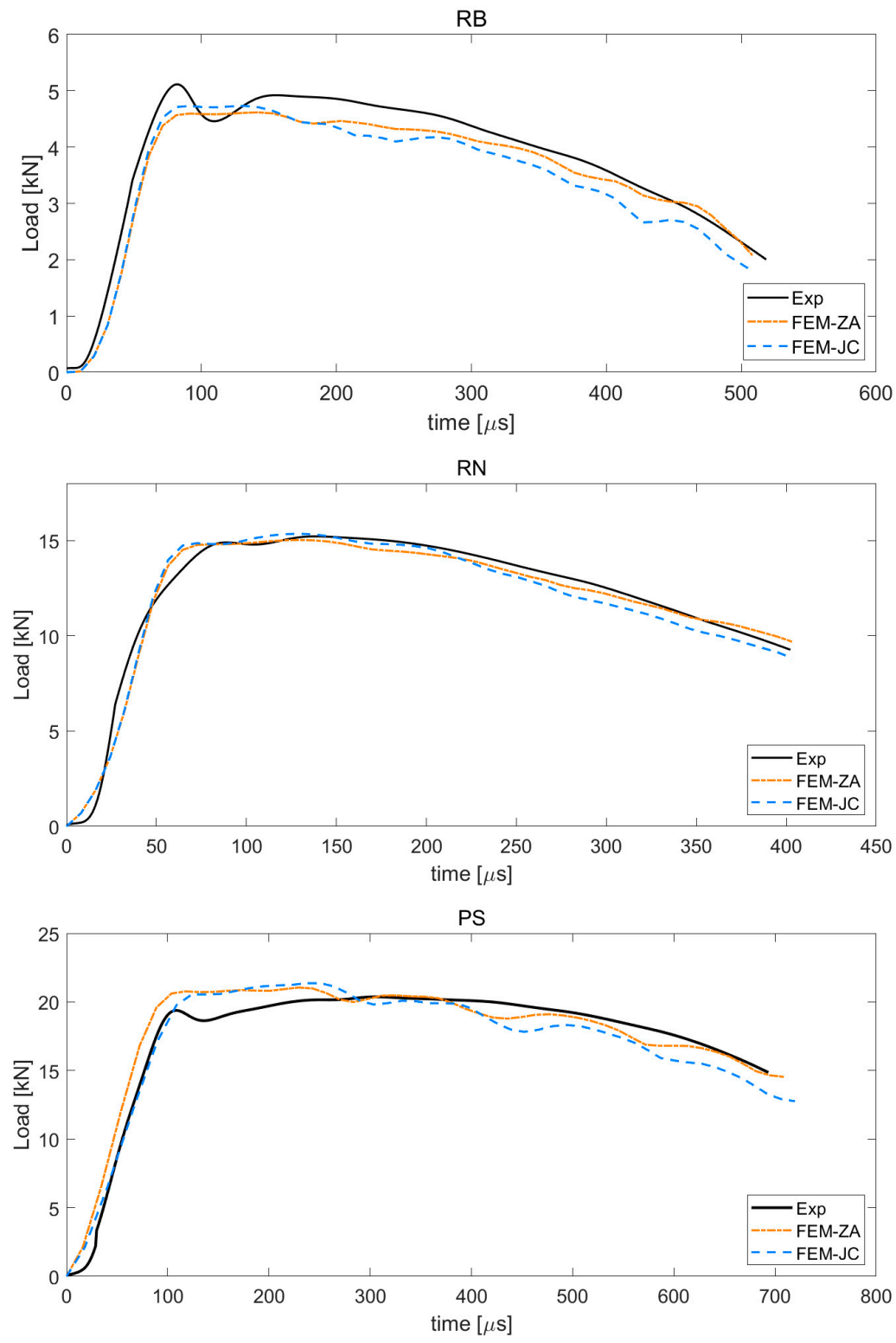

Figure 8. Comparison between experimental and numerical load-displacement curves for RB, RN and PS, for both JC and ZA plasticity models. 
A very good match has also been obtained by analyzing the deformed shape of the samples. More specifically, Figure 9 compares the deformed shapes computed by the FE simulations at the onset of failure with the real observations made during the experimental tests by means of a high-speed camera (model Photron SA4 ${ }^{\circledR}$, used at $100 \mathrm{kfps}$ at resolution of $128 \times 192$ pixel). Notice that the FE-predicted shapes also show the contour map of equivalent plastic strain. Even if only qualitatively, it can be seen that the profile predicted by the FE simulations is in excellent agreement with the real profile. It is worth noting that the profile of the deformed samples could be used quantitatively to extract the plastic flow stress directly, as is done analytically in [45] or numerically in [46]. However, for the sake of sensitivity, it was preferred here to use the more standard inverse FEM approach explained in Section 2.1. Then, the outcome of the numerical simulations performed with the optimized constitutive parameters was subsequently employed to extract the histories of triaxiality, Lode parameter and equivalent plastic strain for each test. Tables 5 and 6 summarize the average value of such parameters according to the different constitutive laws of the material employed, i.e., JC and ZA; the quantities $\varepsilon_{f}^{\text {model }}$ represent the plastic strain under incipient failure conditions predicted by the calibrated damage model. Figure 10 shows the temporal evolution of triaxiality and equivalent plastic strain, as computed by FE analyses up to fracture initiation. The trend of triaxiality can be seen to be very similar for the two calibrated models. The equivalent plastic strains predicted by the two models are identical for the $\mathrm{RN}$ configuration, while a slight overestimation of the strain to failure occurred with the JC model when compared with the ZA model used for the RB and PS configurations.

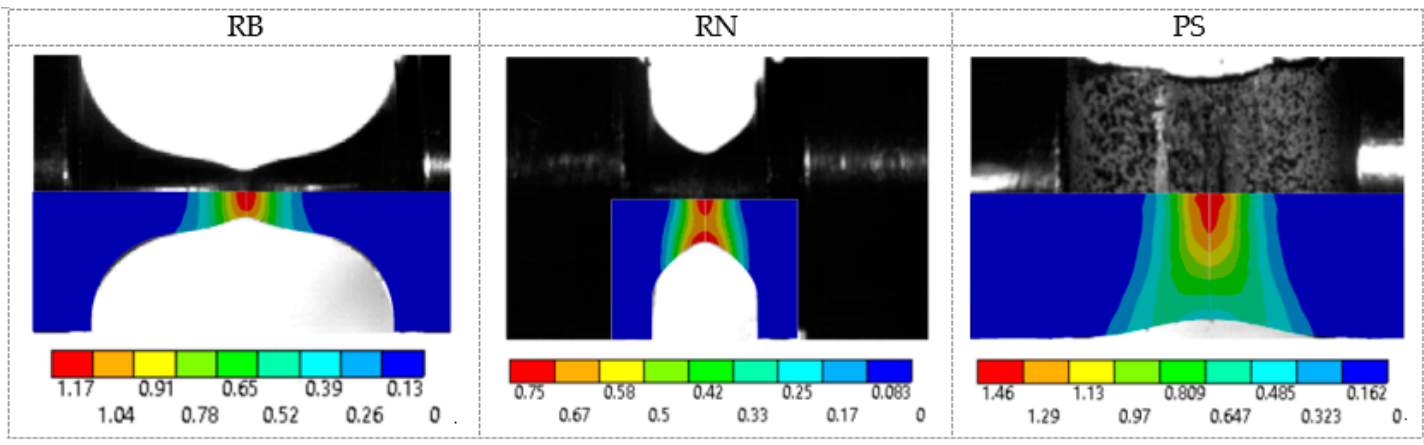

Figure 9. Comparison between the deformed shape observed in the real experiments and the shapes predicted by FE analyses. Color contours represent the equivalent plastic strain distribution computed with the ZA model.

Table 5. Numerical results, JC model: strain rate $(\dot{\varepsilon})$, average $T$ and $X$ values; experimental strain at fracture $\left(\varepsilon_{f}\right)$, strain at fracture $\left(\varepsilon_{f}^{\text {model }}\right)$ and relative error (RE) as predicted by the CCF and BW damage models.

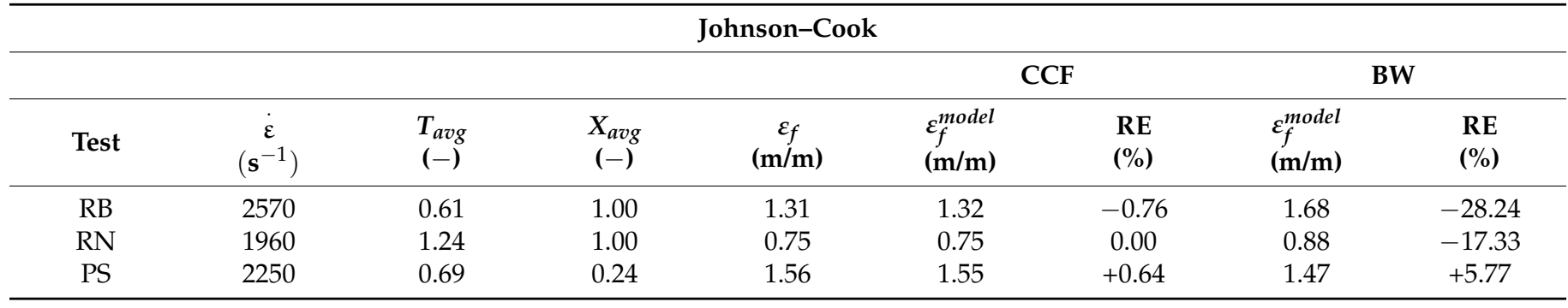


Table 6. Numerical results, ZA model: strain rate $(\dot{\varepsilon})$, average $T$ and $X$ values; experimental strain at fracture $\left(\varepsilon_{f}\right)$, strain at fracture $\left(\varepsilon_{f}^{\text {model }}\right)$ and relative error (RE) as predicted by the CCF and BW damage models.

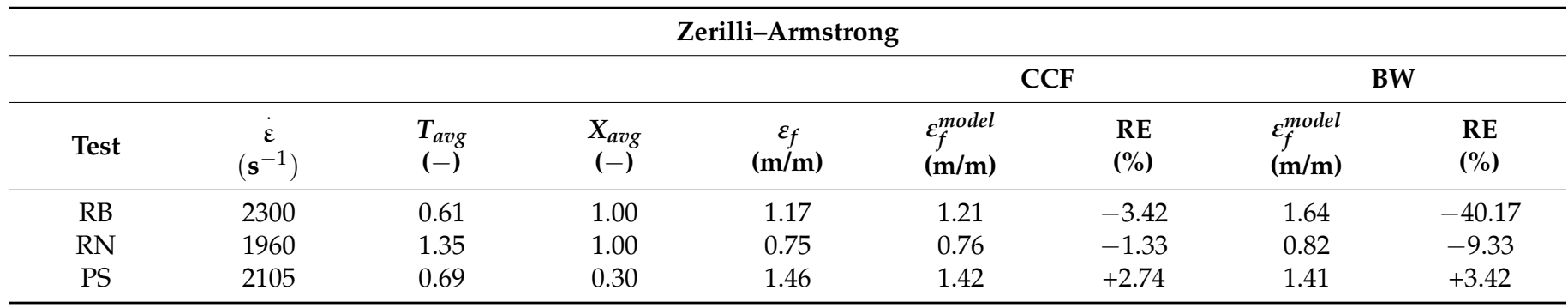
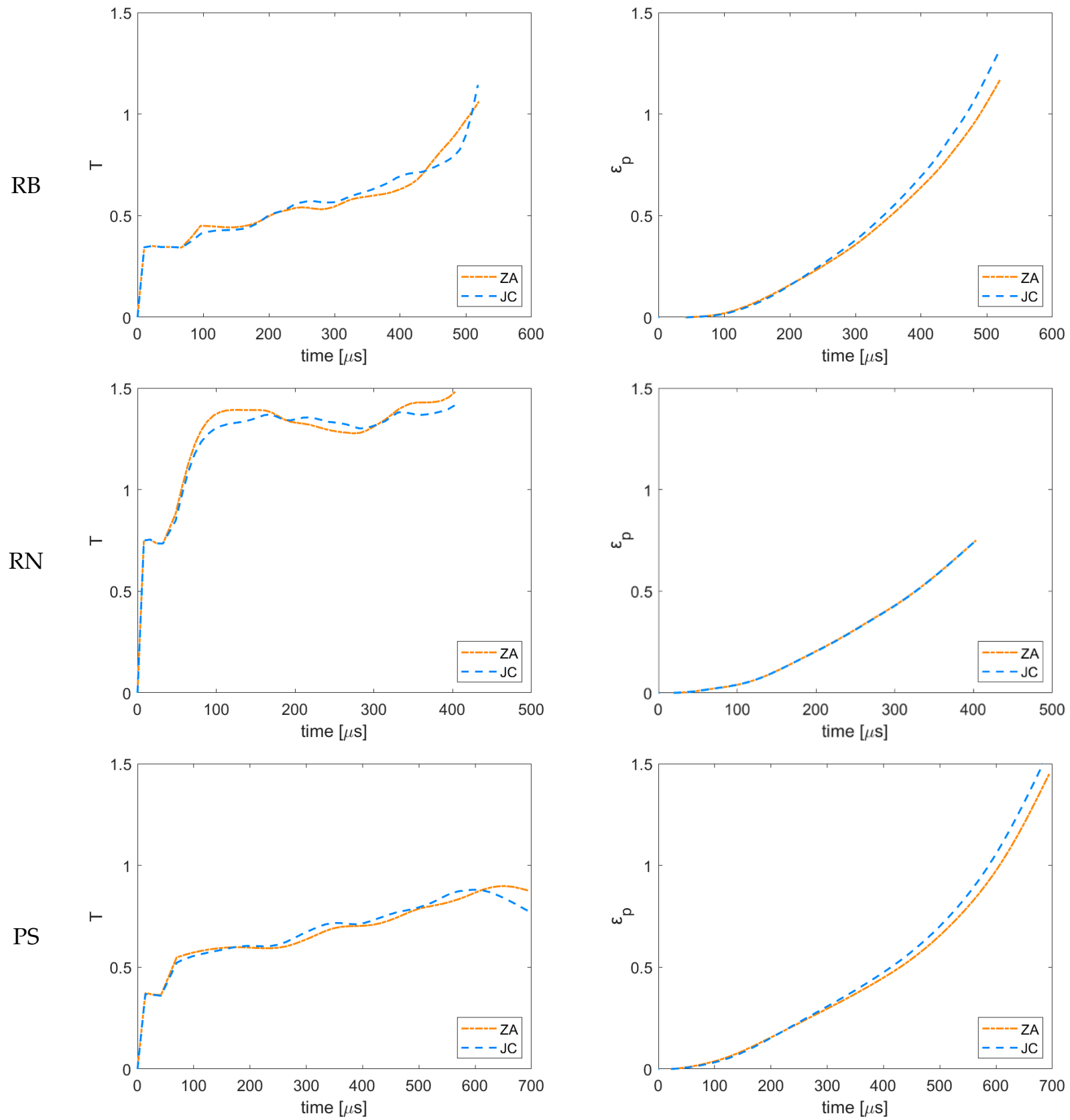

Figure 10. Evolution of triaxiality and equivalent plastic strain computed with the ZA and JC models. 
As a result, the points in space $\left(T_{\text {avg }}, X_{a v g}, \varepsilon_{f}\right)$ of both plasticity models were identified, and, by means of the procedure described in Section 2.2, the parameters granting the best match between the fracture surfaces of the damage models CCF and BW and the experimental points were derived (see Table 7). The resulting errors (SD) were slightly higher for the ZA plasticity model than for the JC. In particular, the fracture surfaces obtained with the CCF damage model exhibited a better match with the experimental data than the fracture surfaces of the BW model, as expressed by the low standard deviation values. Figure 11 illustrates the dynamic fracture surfaces predicted by the $\mathrm{BW}$ and CCF damage models via the JC and ZA plasticity models. In addition to the 3D graphs, a 2D view of the $\varepsilon_{f}$ behavior as a function of the $T$ along curves at constant $X$ has been reported. Overall, all surfaces showed a good match with the experimental points. It is worth noting that the BW model tended to predict a slightly higher ductility than the CCF model.

Table 7. Values of the material damage parameters and the standard deviation (SD) of the minimization.

\begin{tabular}{|c|c|c|c|c|c|c|c|c|}
\hline & & & CCF & & & & BW & \\
\hline $\begin{array}{c}\text { Plasticity } \\
\text { Model }\end{array}$ & $\begin{array}{l}C_{1} \\
(-)\end{array}$ & $\begin{array}{c}C_{2} \\
(-)\end{array}$ & $\begin{array}{c}\beta \\
(-)\end{array}$ & $\begin{array}{c}\gamma \\
(-)\end{array}$ & $\begin{array}{l}\text { SD } \\
(-)\end{array}$ & $\begin{array}{l}C_{1} \\
(-)\end{array}$ & $\begin{array}{c}C_{2} \\
\text { (MPa) }\end{array}$ & $\begin{array}{l}\text { SD } \\
(-)\end{array}$ \\
\hline JC & 0.44 & 0.89 & 0 & 1.00 & $1.1 \times 10^{-2}$ & 0.49 & 470.24 & 0.28 \\
\hline ZA & 0.56 & 0.63 & 0 & 1.00 & $4.1 \times 10^{-2}$ & 0.41 & 428.17 & 0.34 \\
\hline
\end{tabular}
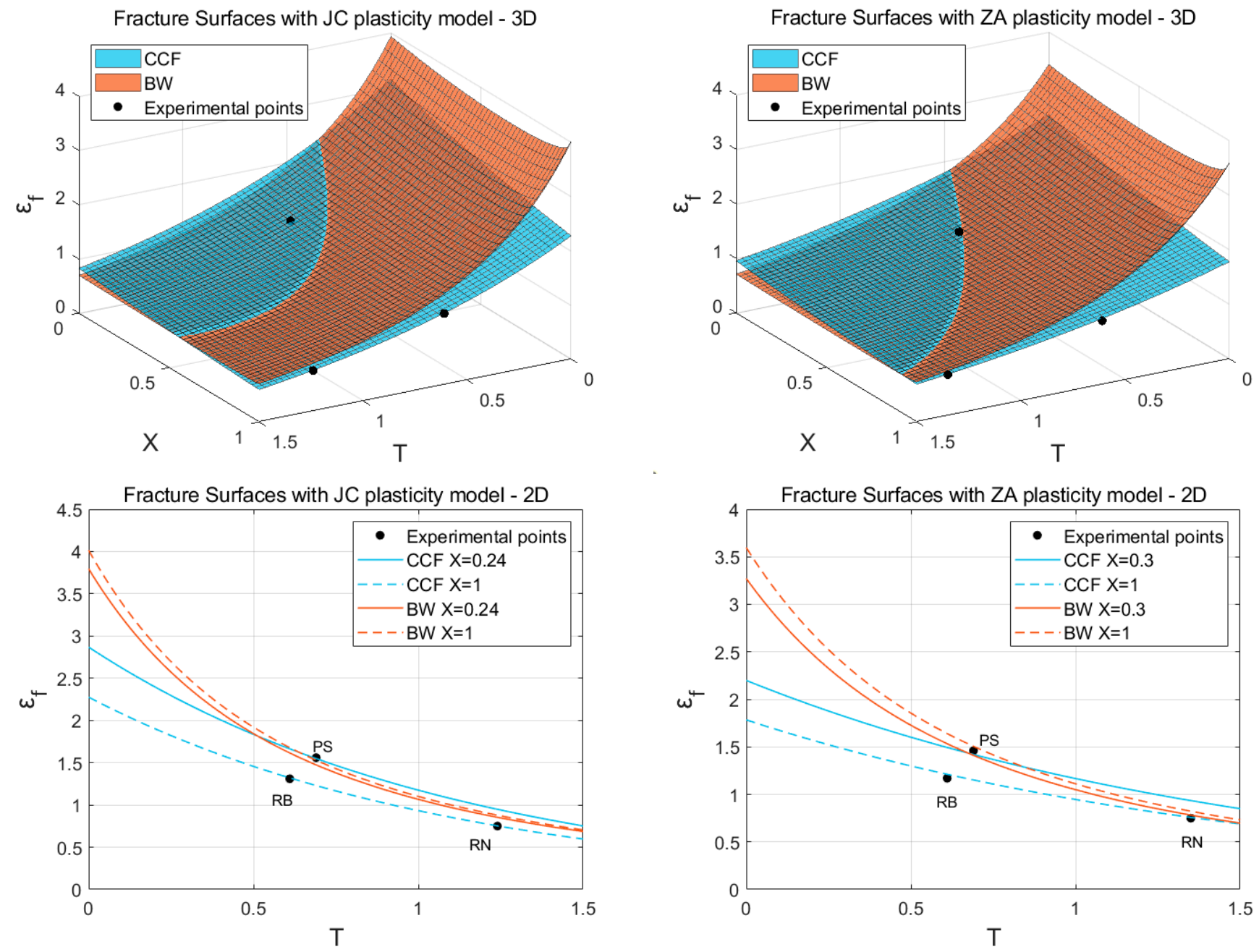

Figure 11. Comparison between the fracture surfaces of BW and CCF, JC and Za plasticity models, and positions of calibration points. 
Figures 12 and 13 present the comparison between the fracture surfaces obtained under static and dynamic conditions (BW and CCF models), obtained by applying as plasticity model the JC and ZA, respectively. All four comparisons suggest an increase in the ductility of the API grade X65 as the strain rate increased. Regarding the BW model, the dynamic fracture surfaces were slightly below the static fracture surfaces with high triaxialities $(\mathrm{T}>1)$; however for lower triaxialities $(\mathrm{T}<1)$, which are most commonly found in actual applications, the dynamic fracture surfaces were clearly higher than the static ones, showing a globally higher ductility. With the combination of the JC-CCF damage model, the increase in ductility with strain rate was very evident, with most of the dynamic fracture surface being above the static one. Only a very small portion of the dynamic surface lay below the static one with a Lode parameter close to 1 . For the last combination of the ZA and CCF models, the dynamic fracture surface exhibited a limited portion below the static one, but globally, an increase in ductility was evident. To summarize, in the above comparisons, there were limited areas wherein ductility under static conditions appeared to be higher than under dynamic conditions. However, it is worth noting that in such areas, the predictive accuracy of the damage models might be limited due to the lack of experimental data presenting triaxialities greater than 1 , or a combination of triaxialities close to 0 and a Lode parameter close to unity. On the contrary, where the experimental points were available, the predictive accuracy was higher, and for those stress states the ductility under dynamic conditions was greater.
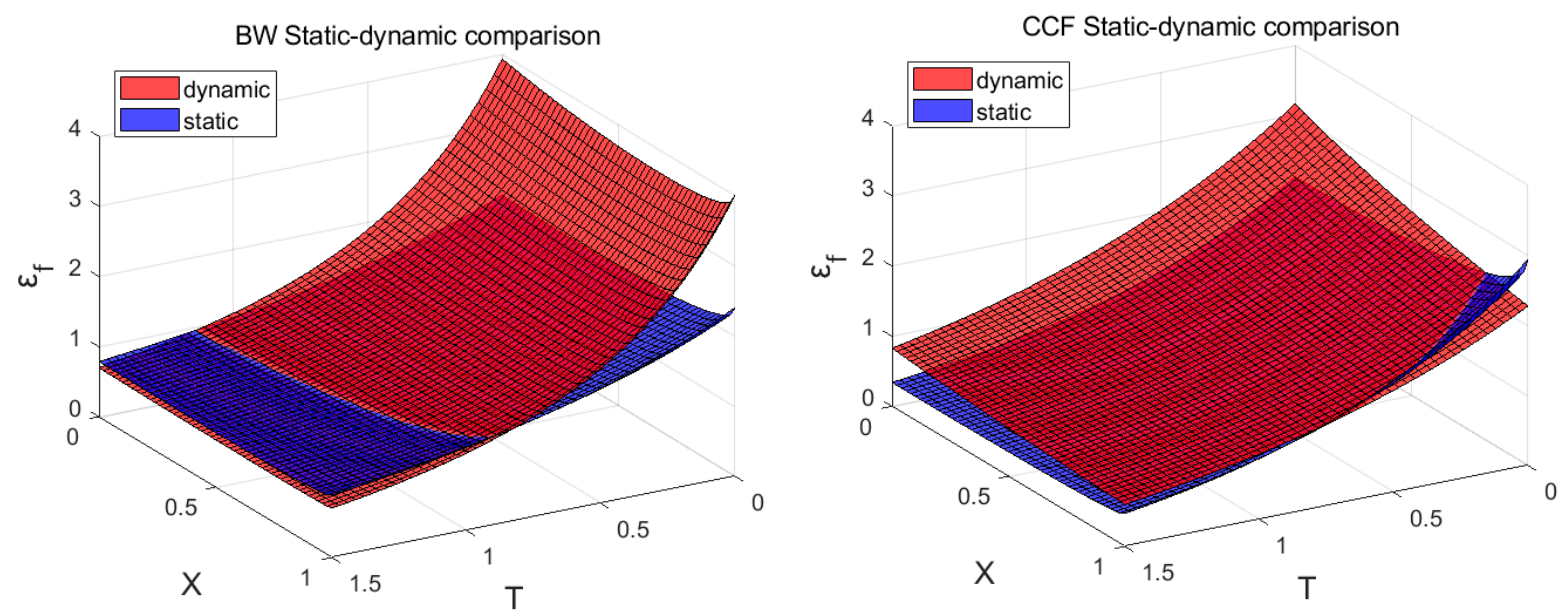

Figure 12. Comparison between the fracture surfaces of the CCF and BW models, obtained under static and dynamic conditions; case of JC plasticity model.
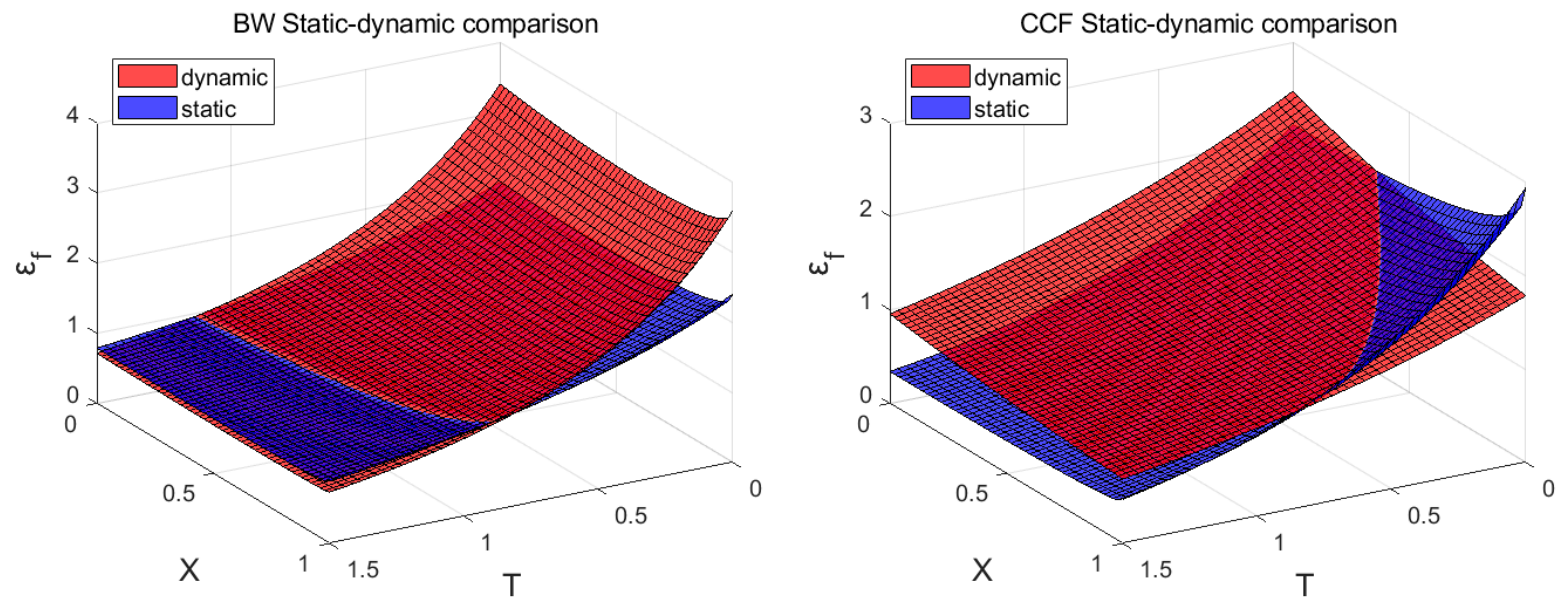

Figure 13. Comparison between the fracture surfaces of the CCF and BW models, obtained under static and dynamic conditions; case of ZA plasticity model. 
It has to be remarked that the very high strain to failures predicted by the models at low triaxialities $(0<\mathrm{T}<0.2)$ might represent an overestimation of the real material ductility. As above, this issue is to be ascribed to the lack of experimental points in the low $T$ range (a dynamic or high-temperature torsion test, characterized by $T=0, X=0$, was not feasible due to the limitations of the available facilities), which could affect the calibration accuracy when the stress states are far from those of the calibration points shown in Tables 5 and 6 .

\section{Tests at Different Temperatures: Results and Discussion}

In the following, the results obtained from the tests performed at different temperatures are presented and compared with the results of the same tests conducted at room temperature, which were taken from a previous work by some of the authors [31]. Again, three repetitions were performed, with very good repeatability. The acquired raw load-crosshead data for the different tests at $600{ }^{\circ} \mathrm{C}$ and $700{ }^{\circ} \mathrm{C}$ are reported in Figure 14.
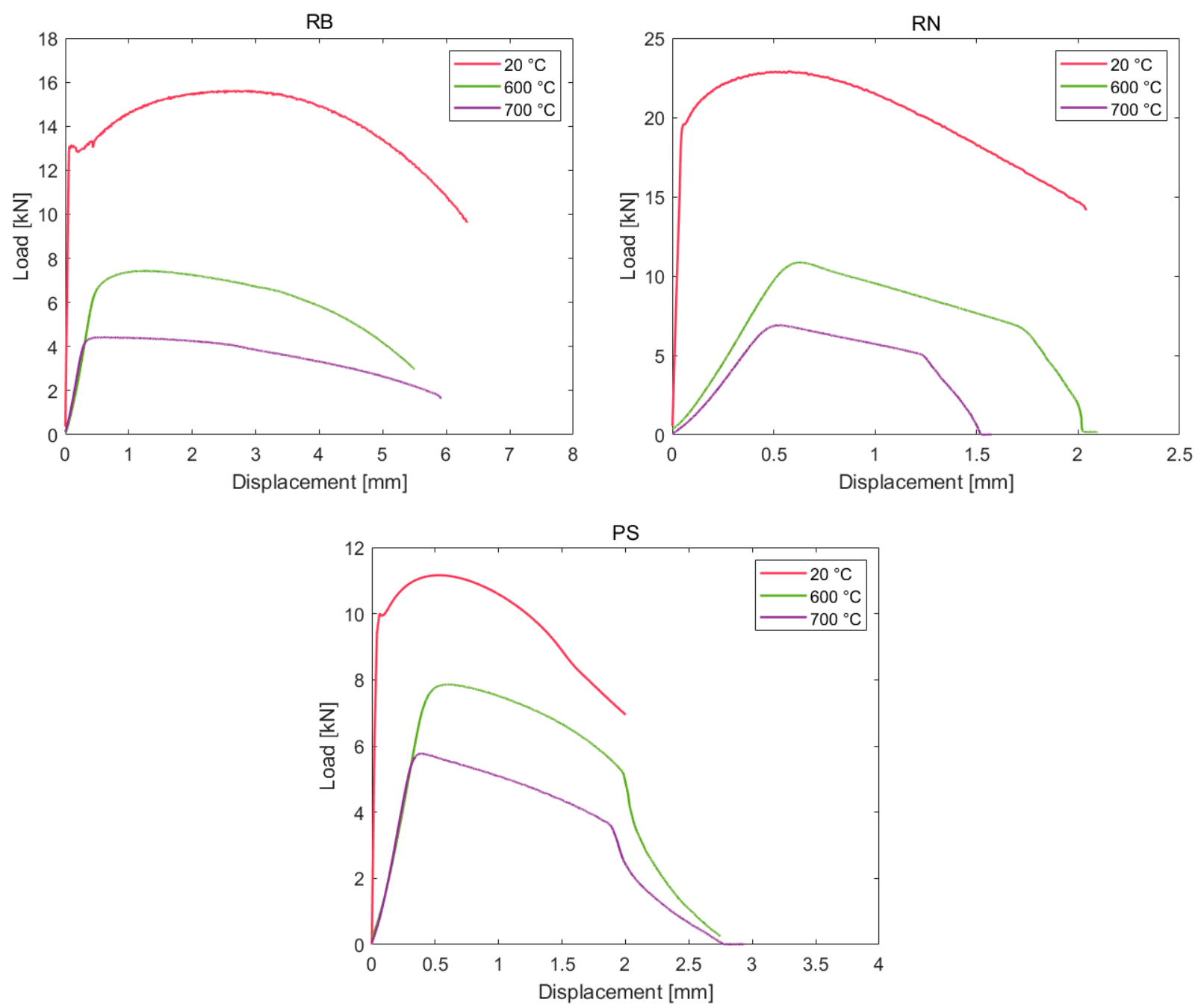

Figure 14. Load-displacement curves of RB, RN and PS tests at different temperatures.

From the RB tests, the stress-strain constitutive behavior could be evaluated at different temperatures, as shown in Figure 15. An inverse procedure was adopted to extend the stress-strain data up to a high strain level. To this end, RB tests were simulated with ANSYS ${ }^{\circledR}$ implicit code, reproducing the exact specimen geometries and loading conditions up to fracture. An optimization algorithm was used to vary the material parameters of a modified Voce's formulation of the material constitutive law (Equation (17)), until the best match between the simulated and experimental global load-displacement data of the 
RB tests could be found. The procedure was repeated for each investigated temperature. The best fitting material parameters are summarized in Table 8.

$$
\sigma=\sigma_{0}+R_{\infty}\left(1-e^{-b \varepsilon_{p}}\right)+R_{0} \varepsilon_{p}
$$

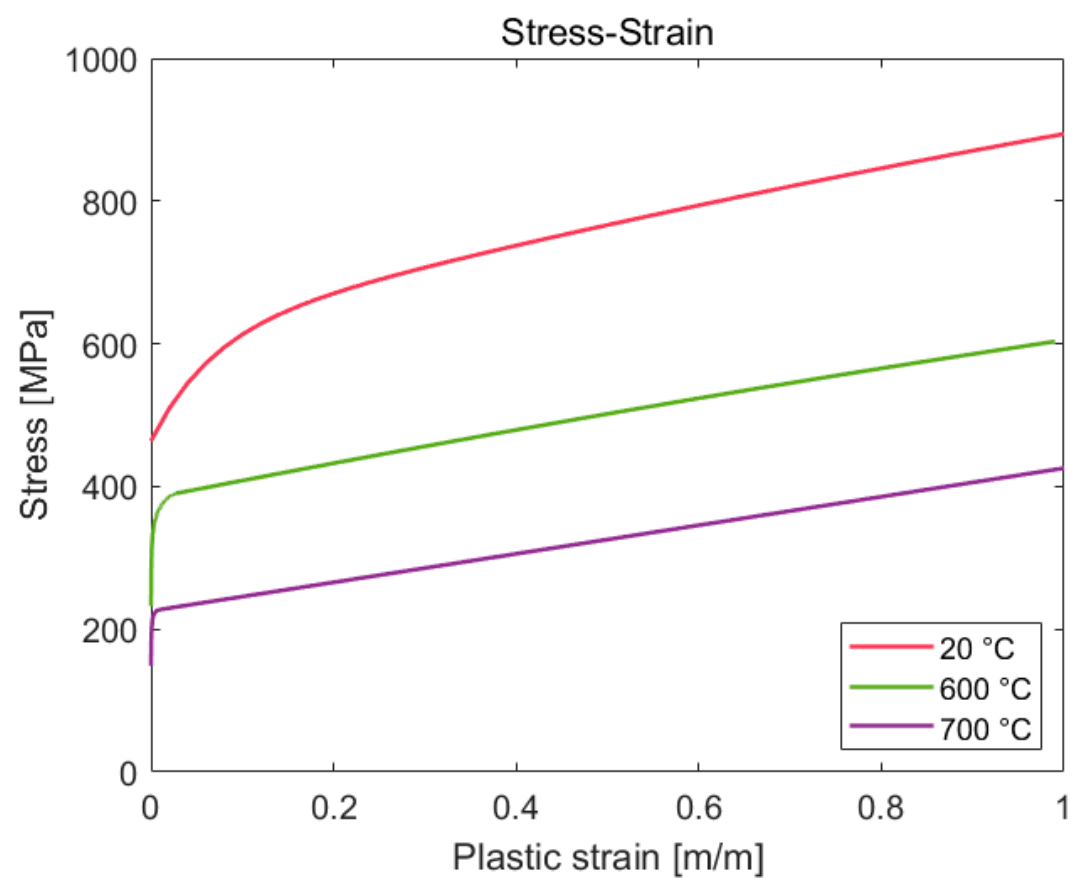

Figure 15. API X65 extended stress-strain curves, at different temperatures.

Table 8. Material parameters of the linear-exponential formulation of the API X65 constitutive behavior, at different temperatures.

\begin{tabular}{ccccc}
\hline & $\begin{array}{c}\sigma_{0} \\
(\mathbf{M P a})\end{array}$ & $\begin{array}{c}\boldsymbol{R}_{\infty} \\
\mathbf{( M P a )}\end{array}$ & $\begin{array}{c}\boldsymbol{b} \\
\mathbf{( - )}\end{array}$ & $\begin{array}{c}\boldsymbol{R}_{0} \\
\mathbf{( M P a})\end{array}$ \\
\hline $20^{\circ} \mathrm{C}$ & 464 & 150 & 15 & 250 \\
$600^{\circ} \mathrm{C}$ & 230 & 160 & 100 & 220 \\
$700^{\circ} \mathrm{C}$ & 150 & 75 & 100 & 200 \\
\hline
\end{tabular}

From Table 8 and Figure 15, it can be seen how material yield stress and ultimate strength decreased with temperature, progressively. For all tests, increasing the temperature to $600{ }^{\circ} \mathrm{C}$ reduced material performance by about $50 \%$, while at $700{ }^{\circ} \mathrm{C}$, the mechanical properties decreased to about $30 \%$ of the corresponding property at room temperature. Even if ductility is expected to increase with temperature, this effect cannot be observed directly from the global data on elongation at fracture, presented in Figure 14. In fact, the elasto-plastic behavior varied with temperature, and global load-displacement curves changed accordingly; at the same time, the information on material ductility is related to the local strain at fracture of the critical points of the specimens, which cannot be directly measured, but must be derived from the FEM analysis of the tests, as shown in the following.

Each experimental test was simulated via the FE code, using the constitutive law of Table 8 , and the same displacement ramp of the experiments, which was stopped at the moment of fracture observation. The local stress and strain histories were extracted from the simulations, then used to calculate T,X (see Equations (7) and (8)) and the equivalent strain at fracture $\varepsilon_{f}$. Table 9 reports the average $T_{a v g}$ and $X_{a v g}$ (which did not change appreciably with temperature) and the values of $\varepsilon_{f}$ retrieved for each geometry at different 
temperatures. The CCF damage model's parameters, calibrated with the same minimization approach described in Section 3, are reported in Table 10.

Table 9. Triaxiality, Lode parameter, and equivalent plastic strain at fracture for different tests and temperatures.

\begin{tabular}{cccc}
\hline & & $\mathcal{E}_{f}(\mathbf{m} / \mathbf{m})$ & PS \\
\hline & RB & RN & 0.79 \\
\hline $0^{\circ} \mathrm{C}$ & 1.43 & 0.86 & 1.32 \\
$700^{\circ} \mathrm{C}$ & 2.20 & 0.90 & 1.63 \\
$7^{\circ} \mathrm{C}$ & 2.40 & 0.60 & 0.75 \\
$T_{\text {avg }}$ & 0.56 & 1.14 & 0.10 \\
$X_{\text {avg }}$ & 1.00 & 1.00 & \\
\hline
\end{tabular}

Table 10. Material parameters of Coppola-Cortese damage model at different temperatures.

\begin{tabular}{ccccccc}
\hline & $C_{1}(-)$ & $C_{2}(-)$ & $\beta$ & $\gamma$ & SD CCF & SD WB \\
\hline $20^{\circ} \mathrm{C}$ & 0.34 & 1.22 & 1.00 & 1.00 & 0.18 & 0.27 \\
$600^{\circ} \mathrm{C}$ & 0.23 & 1.35 & 1.00 & 0.90 & 0.12 & 0.24 \\
$700^{\circ} \mathrm{C}$ & 0.13 & 2.20 & 0.90 & 0.20 & 0.15 & 0.29 \\
\hline
\end{tabular}

Figure 16 shows the fracture surfaces of the calibrated damage model at warm temperatures, using Equation (10), as are usually compared with the corresponding surface at room temperature. The calibration points of Table 9 are also reported. The effect of temperature on the increase in ductility is clear; in fact, the strain at fracture is seen to increase when moving from the lower temperature to the higher. To be rigorous, again, the accuracy of the model's predictions might decrease in the low range of triaxialities $(0<T<0.2)$, due to the lack of torsion test data in the calibration phase; the results in this range of stress states should therefore be considered with caution.

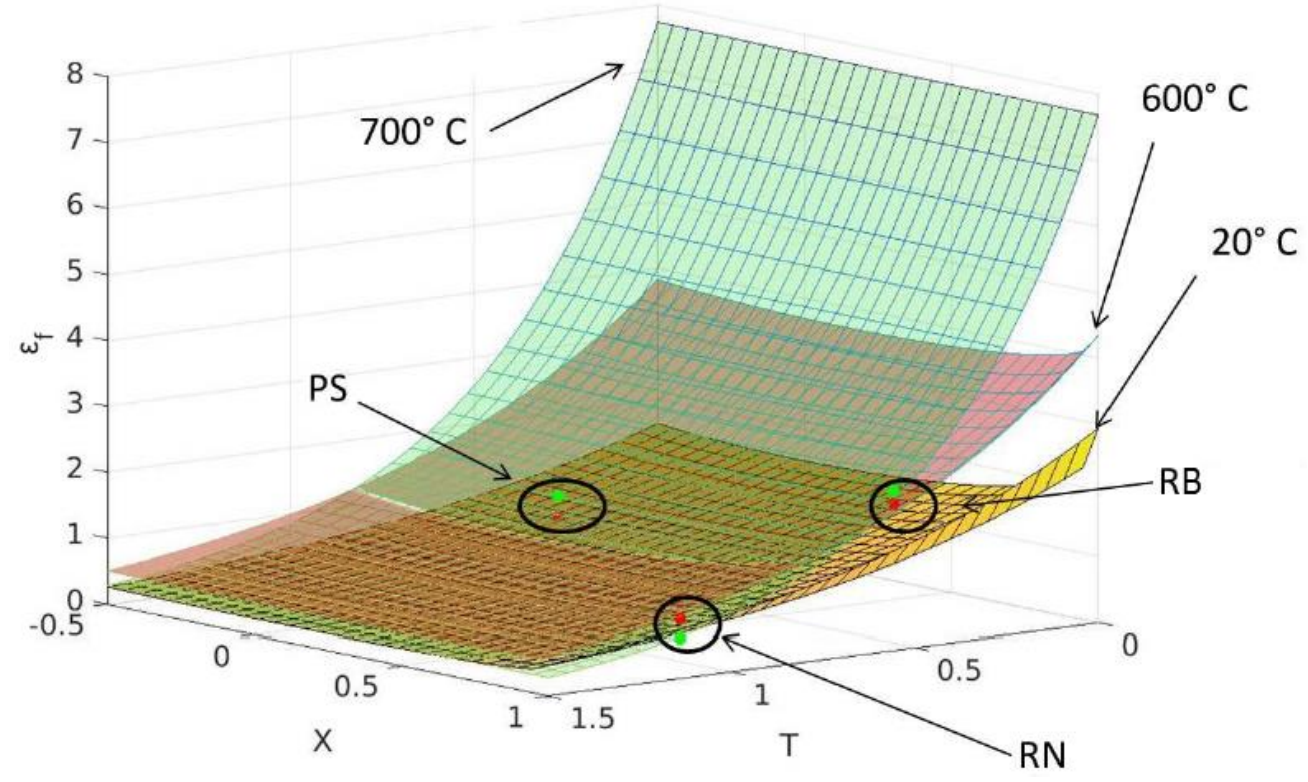

Figure 16. API X65, comparison of fracture surfaces at room temperature, $600{ }^{\circ} \mathrm{C}$ and $700{ }^{\circ} \mathrm{C}$, with the location of calibration points based on experimental tests.

\section{Conclusions}

The plastic and damage behavior of API X65 grade steel was assessed by means of a mixed numerical-experimental procedure. Starting from a quasi-static characterization, the research focused on the identification of the constitutive behavior and the strain to failure 
when the material was subjected to dynamic loading at room temperature, or operated at warm temperatures under quasi-static loading.

Dynamic tests were performed by means of a direct-tension Hopkinson bar system on specimens of three different geometries (round bars, round notched bars and plane strain). The sample dimensions were optimized in order to obtain the desired level of strain rate, triaxiality and Lode parameter. The dynamic tests were also numerically replicated, and an inverse method was used to identify the parameters of the JohnsonCook and Zerilli-Armstrong visco-plastic constitutive models, by comparing the numerical and experimental load-displacement curves. It was found that both constitutive models adequately represented the behavior of the material under the tested conditions.

The Coppola-Cortese and Bai-Wierzbicki models were found to be suitable for capturing experimental evidence under new conditions with good accuracy, comparable to that of the static case at room temperature, as affirmed by the similar standard deviations of the error function of the calibration algorithm. For both damage models, regardless of the visco-plasticity models, the fracture surfaces predicted under dynamic conditions, with an average strain rate of $2000 \mathrm{~s}^{-1}$, were above the quasi-static surfaces over a wide range of stress triaxiality-Lode parameter values (more specifically, for $\mathrm{T}<1$ ), denoting the higher ductility of the API X65 steel at increasing strain rates. The fracture surface was found to slightly depend on the adopted visco-plastic law, with a slightly higher ductility predicted when the Johnson-Cook model was used in place of the Zerilli-Armstrong.

Additionally, the tests at $600{ }^{\circ} \mathrm{C}$ and $700{ }^{\circ} \mathrm{C}$ were executed on similar specimen geometries to quantify the variations in the elasto-plastic response and the overall ductility of the investigated alloy with temperature. Based on the experimental evidence, a standard isotropic plasticity model and the same two damage models were calibrated at the two temperatures. Both damage models predicted a strong increase in ductility with increasing temperature, under any state of stress.

The outcomes may be used as a reference to investigate and optimize the behavior of onshore and offshore pipeline materials subject to accidental impacts or exposed to high temperatures.

Author Contributions: Conceptualization, G.C., L.C. and E.M.; methodology, G.C. and L.C.; validation, F.N. and M.S.; formal analysis, G.C. and M.S.; investigation, G.C, F.N., M.S., L.C. and E.M.; resources, F.N. and E.M.; data curation, G.C., F.N. and E.M.; writing-original draft preparation, G.C., F.N. and L.C.; writing-review and editing, M.S., L.C. and E.M.; visualization, G.C. and F.N.; supervision, M.S., L.C. and E.M.; project administration, M.S. and L.C. All authors have read and agreed to the published version of the manuscript.

Funding: This research received no external funding.

Institutional Review Board Statement: Not applicable.

Informed Consent Statement: Not applicable.

Data Availability Statement: Not applicable.

Conflicts of Interest: The authors declare no conflict of interest.

\section{References}

1. Liang, R.Q.; Khan, A.S. A critical review of experimental results and constitutive models for BCC and FCC metals over a wide range of strain rates and temperatures. Int. J. Plast. 1999, 15, 963-980. [CrossRef]

2. Kocks, U.F.; Argon, A.S.; Ashby, M.F. Thermodynamics and Kinetics of Slip; Pergamon Press: Oxford, UK, 1975.

3. Balasubramanian, S.; Anand, L. Elasto-viscoplastic constitutive equations for polycrystalline fcc materials at low homologous temperatures. J. Mech. Phys. Solids 2002, 50, 101-126. [CrossRef]

4. Testa, G.; Bonora, N.; Ruggiero, A.; Iannitti, G. Flow Stress of bcc Metals over a Wide Range of Temperature and Strain Rates. Metals 2020, 10, 120. [CrossRef]

5. Zerilli, F.J.; Armstrong, R.W. Dislocation-mechanics-based constitutive relations for material dynamics calculations. J. Appl. Phys. 1987, 61, 1816-1825. [CrossRef]

6. Cowper, G.R.; Symonds, P.S. Strain-Hardening and Strain-Rate Effects in the Impact Loading of Cantilever Beams; Technical Report; Brown University: Providence, RI, USA, 1957. 
7. Bodner, S.R.; Partom, Y. Constitutive equations for elastic-viscoplastic strain-hardening materials. J. Appl. Mech. 1975, 42, 385-389. [CrossRef]

8. Johnson, G.R.; Cook, W.H. Fracture characteristics of three metals subjected to various strains, strain rates, temperatures and pressures. Eng. Fract. Mech. 1985, 21, 31-48. [CrossRef]

9. Cao, T.S. Models for ductile damage and fracture prediction in cold bulk metal forming processes: A review. Int. J. Mater. Form. 2017, 10, 139-171. [CrossRef]

10. Khan, A.S.; Baig, M.; Choi, S.-H.; Yang, H.-S.; Sun, X. Quasi-static and dynamic responses of advanced high strength steels: Experiments and modeling. Int. J. Plast. 2012, 30-31, 1-17. [CrossRef]

11. Roth, C.C.; Mohr, D. Effect of strain rate on ductile fracture initiation in advanced high strength steel sheets: Experiments and modeling. Int. J. Plast. 2014, 56, 19-44. [CrossRef]

12. Oliver, S.; Jones, T.B.; Fourlaris, G. Dual phase versus TRIP strip steels: Microstructural changes as a consequence of quasi-static and dynamic tensile testing. Mater. Charact. 2007, 58, 390-400. [CrossRef]

13. Huh, H.; Kim, S.B.; Song, J.H.; Lim, J.H. Dynamic tensile characteristics of TRIP-type and DP-type steel sheets for an auto-body. Int. J. Mech. Sci. 2008, 50, 918-931. [CrossRef]

14. Huh, J.; Huh, H.; Lee, C.S. Effect of strain rate on plastic anisotropy of advanced high strength steel sheets. Int. J. Plast. 2013, 44, 23-46. [CrossRef]

15. Depraetere, R.; Cauwels, M.; De Waele, W.; Depover, T.; Verbeken, K.; Hertelé, S. Calibrating a ductile damage model for two pipeline steels: Method and challenges. Procedia Struct. Integr. 2020, 28, 2267-2276. [CrossRef]

16. $\mathrm{Wu}, \mathrm{Y}$; Z Zhang, Y.; Li, L. Analysis of ductile damage changes of pipelines with unconstrained dents in rebound process. Eng. Fail Anal. 2021, 120, 105071. [CrossRef]

17. Dong, X.X.; Shen, Y.F.; Xue, W.Y.; Jia, N. Improved work hardening of a medium carbon-TRIP steel by partial decomposition of retained austenite. Mater. Sci. Eng. A 2021, 803, 140504. [CrossRef]

18. Rice, J.R.; Tracey, D.M. On the ductile enlargement of voids in triaxial stress fields. J. Mech. Phys. Solids 1969, 17, 201-217. [CrossRef]

19. Gurson, A.L. Continuum theory of ductile rupture by void nucleation and growth. Part I. Yield criteria and flow rules for porous ductile media. J. Eng. Mater. Technol. 1977, 99, 2-15. [CrossRef]

20. Tvergaard, V.; Needleman, A. Analysis of the cup-cone fracture in a round tensile bar. Acta Mater. 1984, 32, 157-169. [CrossRef]

21. Nahshon, K.; Hutchinson, J.W. Modification of the Gurson model for shear failure. Eur. J. Mech. A Solids 2008, 27, 1-17. [CrossRef]

22. Bonora, N. A nonlinear CDM model for ductile failure. Eng. Fract. Mech. 1997, 58, 11-28. [CrossRef]

23. Bonora, N.; Milella, P.P. Constitutive modeling for ductile metals behavior incorporating strain rate, temperature and damage mechanics. Int. J. Impact Eng. 2001, 26, 53-64. [CrossRef]

24. Cockcroft, M.G.; Latham, D.J. Ductility and the workability of metals. J. Inst. Met. 1968, 96, 33-39.

25. Bao, Y.; Wierzbicki, T. On fracture locus in the equivalent strain and stress triaxiality space. Int. J. Mech. Sci. 2004, 46, 81-98. [CrossRef]

26. Wierzbicki, T.; Xue, L. On the Effect of the Third Invariant of the Stress Deviator on Ductile Fracture; Technical Report; Impact and Crashworthiness Laboratory, Massachusetts Institute of Technology: Cambridge, MA, USA, 2005.

27. Bai, Y.; Wierzbicki, T. A new model of metal plasticity and fracture with pressure and lode dependence. Int. J. Plast. 2008, 24, 1071-1096. [CrossRef]

28. Bai, Y.; Wierzbicki, T. Application of extended Mohr-Coulomb criterion to ductile fracture. Int. J. Fract. 2010, 161, 1. [CrossRef]

29. Fossum, A.; Brannon, R. On a viscoplastic model for rocks with mechanism-dependent characteristic times. Acta Geotech. 2006, 1, 89-106. [CrossRef]

30. Coppola, T.; Cortese, L.; Folgarait, P. The effect of stress invariants on ductile fracture limit in steels. Eng. Fract. Mech. 2009, 76, 1288-1302. [CrossRef]

31. Cortese, L.; Coppola, T.; Campanelli, F.; Campana, F.; Sasso, M. Prediction of ductile failure materials for onshore and offshore pipeline applications. Int. J. Damage Mech. 2014, 23, 104-123. [CrossRef]

32. Johnson, G.R.; Cook, W.H. A constitutive model and data for metals subjected to large strains, high strain rates, and high temperatures. In Proceedings of the Seventh International Symposium on Ballistics, International Ballistics Committee, Hague, The Netherlands, 19-21 April 1983; pp. 541-547.

33. Mancini, E.; Sasso, M.; Rossi, M.; Chiappini, G.; Newaz, G.; Amodio, D. Design of an Innovative System for Wave Generation in Direct Tension-Compression Split Hopkinson Bar. J. Dyn. Behav. Mater. 2015, 1, 201-213. [CrossRef]

34. Martarelli, M.; Mancini, E.; Lonzi, B.; Sasso, M. Sensor calibration of polymeric Hopkinson bars for dynamic testing of soft materials. Meas. Sci. Technol. 2018, 17, 761-775. [CrossRef]

35. Yanagimoto, J.; Oyamada, K. Mechanism of springback-free bending of high-strength steel sheets under warm forming conditions. CIRP Ann. 2007, 56, 265-268. [CrossRef]

36. Neugebauer, R.; Altan, T.; Geiger, M.; Kleiner, M.; Sterzing, A. Sheet metal forming at elevated temperatures. CIRP Ann. 2006, 55, 793-816. [CrossRef]

37. Rusin, A.; Stolecka-Antczak, K.; Kapusta, K.; Rogozinski, K.; Rusin, K. Analysis of the Effects of Failure of a Gas Pipeline Caused by a Mechanical Damage. Energies 2021, 14, 7686. [CrossRef] 
38. Kristoffersen, M.; Børvik, T.; Westermann, I.; Langseth, M.; Hopperstad, O.S. Impact against X65 steel pipes-An experimental investigation. Int. J. Solids. Struct. 2013, 50, 3430-3445. [CrossRef]

39. Mirone, G.; Barbagallo, R. Coupling of temperature and strain in thermal softening of a stainless steel at low and high strain rates. Procedia Struct. Integr. 2019, 24, 259-266. [CrossRef]

40. Hopkinson, B. A Method of Measuring the Pressure Produced in the Detonation of Explosives or by the Impact of Bullets. Proc. R. Soc. Lond. A 1914, 89, 411-413. [CrossRef]

41. Kolsky, H. An Investigation of the Mechanical Properties of Materials at Very High Rates of Loading. Proc. Phys. Soc. B 1949, 62, 676-700. [CrossRef]

42. Song, B.; Chen, W. Split Hopkinson Kolsky Bar: Design Testing and Applications; Springer: New York, NY, USA, 2010.

43. Sasso, M.; Mancini, E.; Cortese, L.; Nalli, F. Design and Optimization of Dynamic Test Samples for Ductile Damage Assessment. In Proceedings of the DYMAT 2018-12th International Conference on the Mechanical and Physical Behaviour of Materials under Dynamic Loading, Arcachon, France, 9-14 September 2018. [CrossRef]

44. Mori, K.; Saito, S.; Maki, S. Warm and hot punching of ultra high strength steel sheet. CIRP Ann. 2008, 57, 321-324. [CrossRef]

45. Peroni, L.; Scapin, M.; Fichera, C. An advanced identification procedure for material model parameters based on image analysis. In Proceedings of the 10th European LS-DYNA Conference, Würzburg, Germany, 15-17 June 2015.

46. Sasso, M.; Fardmoshiri, M.; Mancini, E.; Rossi, M.; Cortese, L. High speed imaging for material parameters calibration at high strain rate. Eur. Phys. J. Spec. Top. 2016, 225, 295-309. [CrossRef] 